NBER WORKING PAPER SERIES

GLOBAL MELTING? THE ECONOMICS OF DISINTEGRATION OF THE GREENLAND
ICE SHEET

William D. Nordhaus

Working Paper 24640

http://www.nber.org/papers/w24640

\author{
NATIONAL BUREAU OF ECONOMIC RESEARCH \\ 1050 Massachusetts Avenue \\ Cambridge, MA 02138 \\ May 2018
}

The author is grateful for helpful comments from many researchers and colleagues. Particular thanks go to Klaus Keller, who has pioneered work on the interface of economics and earth sciences. Additionally, I am grateful for feedback from Richard Alley, Eli Fenichel, Ken Gillingham, Matt Kotchen, Robert Mendelsohn, Joe Shapiro, and Martin Weitzman. The research was supported by the by the U.S. National Science Foundation and the U.S. Department of Energy as well as by a fellowship from the Carnegie Foundation. All views and errors are the responsibility of the author. The author declares no financial conflict of interest. The views expressed herein are those of the author and do not necessarily reflect the views of the National Bureau of Economic Research.

NBER working papers are circulated for discussion and comment purposes. They have not been peer-reviewed or been subject to the review by the NBER Board of Directors that accompanies official NBER publications.

(C) 2018 by William D. Nordhaus. All rights reserved. Short sections of text, not to exceed two paragraphs, may be quoted without explicit permission provided that full credit, including ( $)$ notice, is given to the source. 
Global Melting? The Economics of Disintegration of the Greenland Ice Sheet

William D. Nordhaus

NBER Working Paper No. 24640

May 2018

JEL No. H4,Q5,Q54

\begin{abstract}
$\underline{\text { ABSTRACT }}$
Concerns about the impact on large-scale earth systems have taken center stage in the scientific and economic analysis of climate change. The present study analyzes the economic impact of a potential disintegration of the Greenland Ice Sheet (GIS). The method is to combine a small geophysical model of the GIS with the DICE integrated assessment model. The result shows that the GIS is likely to disappear over the next millennium or so without climate policy, but an active climate policy may prevent the GIS from crossing the threshold of irreversibility. Additionally, the study estimates the impact of the GIS on the social cost of carbon (SCC) and finds that adding GIS dynamics would add less than 5\% to the SCC under alternative discount rates and estimates of the GIS dynamics. Simulations of geo-engineering options indicate that the dynamics of disintegration and rebuilding are extremely asymmetric, implying that GIS disintegration should be treated as irreversible.
\end{abstract}

William D. Nordhaus

Yale University, Department of Economics

28 Hillhouse Avenue

Box 208264

New Haven, CT 06520-8264

and NBER

william.nordhaus@yale.edu 


\title{
Global Melting? \\ The Economics of Disintegration of the Greenland Ice Sheet
}

\author{
William Nordhaus ${ }^{1}$ \\ Yale University, New Haven, CT
}

April 25, 2018

\begin{abstract}
Concerns about the impact on large-scale earth systems have taken center stage in the scientific and economic analysis of climate change. The present study analyzes the economic impact of a potential disintegration of the Greenland Ice Sheet (GIS). The method is to combine a small geophysical model of the GIS with the DICE integrated assessment model. The result shows that the GIS is likely to disappear over the next millennium or so without climate policy, but an active climate policy may prevent the GIS from crossing the threshold of irreversibility.

Additionally, the study estimates the impact of the GIS on the social cost of carbon (SCC) and finds that adding GIS dynamics would add less than $5 \%$ to the SCC under alternative discount rates and estimates of the GIS dynamics. Simulations of geo-engineering options indicate that the dynamics of disintegration and rebuilding are extremely asymmetric, implying that GIS disintegration should be treated as irreversible.
\end{abstract}

\section{Overview and Summary}

The future of the mammoth Greenland Ice Sheet (GIS) is one of the largest and most complicated issues facing environmental policy in the coming years. Complete disintegration of the GIS would raise the level of the oceans by more than 7 meters, inundating many of the world's major human settlements. Paleoclimatic findings, as well as ice-sheet modeling, indicate that the current trajectory of global temperatures would lead to nearly complete disintegration over the coming millennia. The critical questions are, how fast will the ice sheet

1 The author is grateful for helpful comments from many researchers and colleagues. Particular thanks go to Klaus Keller, who has pioneered work on the interface of economics and earth sciences. Additionally, I am grateful for feedback from Richard Alley, Eli Fenichel, Ken Gillingham, Matt Kotchen, Robert Mendelsohn, Joe Shapiro, and Martin Weitzman. The research was supported by the by the U.S. National Science Foundation and the U.S. Department of Energy as well as by a fellowship from the Carnegie Foundation. All views and errors are the responsibility of the author. The author declares no financial conflict of interest. [Modeling the GIS-042518a.docx] 
decline, and what can be done to stop the disintegration and resulting inundation?

The present study examines economic aspects of the disintegration of the GIS by incorporating a small reduced-form model of the GIS into the DICE model of the economics of climate change. Studies find that a rise in temperature a few degrees above the current levels will lead to a nearly total icesheet loss. However, the warming at which the ice sheet will disappear is poorly understood and ranges from $1 \frac{1 / 2}{2}$ to $4{ }^{\circ} \mathrm{C}$ above twentieth-century levels. It is unclear whether there is a single set or multiple sets of equilibria of temperature and GIS volume, but the best modeling evidence suggests multiple equilibria with hysteresis.

An additional factor is the dynamics of disintegration and rebuilding between equilibria. Modeling studies indicate that the path of melting is slow, with the central estimate being that, at a $6^{\circ} \mathrm{C}$ global warming, the GIS would lose $10 \%$ of its volume in four to five centuries. The exact dynamics vary widely among alternative models.

The current study develops a model of GIS equilibrium and dynamics that is based on current studies but sufficiently small to integrate fully into an economic model. The result is the DICE-GIS model, which includes the standard components of the DICE-2016R2 integrated assessment model. Based on this augmented model, the study then examines baseline and optimal climate policies along with different constraints, parameters, and discount rates.

Here are the major results of the study. First, the study finds that a "baseline" path of no climate policy will lead to the gradual disintegration of the GIS over the coming millennium. The ice-sheet decline is slow, with a GIS halflife of approximately eight centuries in the baseline path, but once past the tipping points, disintegration is difficult to reverse.

Second, strong climate policy can stop the GIS decline well short of complete disintegration or critical tipping points. Full-scale ice-sheet models have different predictions about hysteresis and reversibility. However, most would agree that, if temperature peaks at 2 to $3{ }^{\circ} \mathrm{C}$ and then declines relatively soon, the ice sheet will stabilize at somewhere between $70 \%$ and $95 \%$ of current volume.

Third, it is useful to consider the impact of the GIS on climate policy either through including a damage coefficient or through putting a volumetric limit on the decline of the GIS. These give roughly the same answers for the social cost of carbon at moderate discount rates and standard melt rates and differ significantly only at tight volumetric constraints and high melt rates. 
Fourth, a useful way of understanding the impact of GIS disintegration on climate policy is to estimate how much adding GIS damages or volumetric constraints changes the social cost of carbon (SCC). The addition is near zero at moderate discount rates and as high as $5 \%$ of the total SCC at very low discount rates and high melt rates. At the discount rate used by the US government, the addition of GIS damages to the SCC is essentially zero.

Fifth, the study considers four alternative approaches to dynamics: linear, non-linear monotonic, irreversible, and hysteretic. The basic finding is that, although the exact numbers and timing differ slightly, the results are essentially the same for all approaches.

Finally, the consideration of geo-engineering options leads to a surprising and important implication. Simulations with DICE-GIS as well as with larger scale ice-sheet models indicate that there is a sharp non-linearity in the response of ice-sheet changes to temperature. A policy that reduces global and GIS temperature to pre-industrial levels produces a very slow rebuilding of the GIS. In the estimates here, the rebuild rate in the cold (geo-engineered) scenario is less than one-tenth of the decline rate in the warm period. From an economic and policy perspective, the implication is that disintegration should be viewed as an irreversible process. Put differently, while the GIS may eventually rebuild to its current volume if temperature declines to pre-industrial levels, the rate of rebuilding is so slow that the damage cannot be undone within the perspective of climate policy and human settlements.

\section{Greenland Ice Sheet in the Context of Tipping of Large Earth Systems}

Concerns about the impact of climate change on large-scale and unmanageable earth systems have taken center stage in the scientific and economic analysis of climate change. Continued warming threatens to push large-scale earth systems beyond tipping points. This issue was highlighted in an influential paper on key "tipping points" of the earth system (Lenton et al. 2008). They write:

Human activities may have the potential to push components of the Earth system past critical states into qualitatively different modes of operation, implying large-scale impacts on human and ecological systems. Examples that have received recent attention include the potential collapse of the Atlantic thermohaline circulation (THC), dieback of the Amazon rainforest, and decay of the Greenland ice sheet (GIS). Such phenomena have been described as "tipping points" following the popular notion that, at a particular moment in time, a small change can have large, long-term consequences for a system...

Three important types of non-linear responses considered here are systems that are reversible, irreversible or highly asymmetrical, and hysteretic (displaying path-dependence or hysteresis). 
Here are simple definitions of these processes: A reversible system is one with no memory, as with a stick that bends then returns to its original position. An irreversible or highly asymmetrical system is one that breaks or changes to a new state once a threshold is passed, as with a stick that is broken when bent too far. A hysteretic system is one with memory of its history. Here an example would be the consequence of an abrupt climatic event. With a given climate, certain species (such as dinosaurs) would thrive, whereas, after a sharp climatic change (such as a sharp cooling for a few centuries), an entirely new ecosystem might evolve when the climate returned to its original state.

In developing the DICE-GIS model, it is necessary to find a numerical structure that represents GIS behavior in a robust and parsimonious manner. Call this a "reduced-form model." The model must be simple enough to include in a few equations, yet reliable enough to represent the larger models. For example, the standard SICOPOLIS model has thousands of equations and clearly cannot be run in an optimization model.

The literature on the impacts of major or catastrophic changes in earth systems is vast. In the scientific domain, the IPCC reviewed several potential major "abrupt" changes (IPCC, Science, 2013, section 12.5.5). The report concluded, "Several components or phenomena in the climate system could potentially exhibit abrupt or nonlinear changes, but for many phenomena, there is low confidence and little consensus on the likelihood of such events over the 21st century."

Studies of complex non-linear dynamic processes have a long research history in ecology and economics. In the study of climate change, integrated assessment models (IAMs) have analyzed Atlantic circulation collapse and icesheet collapse (see Keller et al. 2004 and Diaz and Keller 2016). The methods applied here can also be used for the Antarctic Ice Sheet, which has been examined in other studies (Bakker et al. 2017 and Wong et al. 2017). To date, IAMs have not attempted to link structural earth-systems models of the abrupt phenomena mentioned above to economic models. That is the approach taken in the present study.

The plan of the paper is the following. It begins with a discussion of the structure of the Greenland Ice Sheet. This is followed by modeling details and results. The subsequent sections analyze alternative equilibrium structures and uncertainty. The final section presents reservations and qualifications. 


\section{Further Analysis of the Greenland Ice Sheet}

With few exceptions, modeling "tipping points" and "catastrophes" has been schematic and has not relied on realistic physical models of the phenomena of concern. Exceptions are Keller and Bradford (1995), Keller, Hall, Kim, Bradford, and Oppenheimer (2005), and a 2016 session of the American Economic Association on valuing climate change catastrophes (see Diaz and Keller 2016). The study by Bakker et al. (2016) develops a calibrated model ("SIMPLE") similar to the one used here to test the impacts of geo-engineering. To my knowledge, none of the studies incorporates simplified structural geophysical models within an economic framework.

This section begins with a review of current physical GIS models and what current science suggests about the dynamic structure of giant ice sheets. It then develops a manageable dynamic model of the GIS and to include that in the DICE integrated assessment model.

\section{Physical models of the Greenland Ice Sheet}

A brief description of the GIS may be useful for non-specialists.

Greenland is the world's largest island, with an area of 2.17 million $\mathrm{km}^{2}$ or about five times the size of California.The ice sheet covers 1.76 million $\mathrm{km}^{2}$, or about $80 \%$ of the area, with an average thickness of 1,667 meters, for a total of 2.85 million $\mathrm{km}^{3}$ of ice. While the ice sheet has waxed and waned during ice ages and warm periods, it appears to have remained partially glaciated for at least 1 million years. Over the last century, the GIS has been volumetrically stable, with precipitation (adding volume) offset by melting and iceberg discharge (reducing volume). However, the GIS during the last decade has lost about $280 \mathrm{~km}^{3}$ annually, which is the equivalent of $0.8 \mathrm{~mm}$ of sea-level rise equivalent (SLRe) per year.

The Fifth Assessment Report of the Intergovernmental Panel on Climate Change, Science (IPCC 2013) reviewed the evidence on the GIS. It concluded that (1) several stable states of the Greenland Ice Sheet might exist; (2) the ice sheet might irreversibly shrink to a stable smaller state once a warming threshold is crossed for a certain amount of time; (3) the critical duration would depend on how far the temperature threshold has been exceeded and for how long; and (4) an irreversible decrease of the Greenland ice sheet appears very unlikely in the $21^{\text {st }}$ century but is likely on multi-centennial to millennial time scales in the largest warming scenarios. See Appendix $C$ for a further discussion.

Models find a threshold temperature for GIS disintegration variously between 1 and $5{ }^{\circ} \mathrm{C}$ above baseline levels (mid-twentieth century). However, it is misleading to suggest that complete GIS disintegration is inevitable when the temperature threshold is passed because the disintegration is relatively slow. 
Rather, as the IPCC (2013) notes, "The complete loss of the ice sheet is not inevitable because it has a long time scale (tens of millennia near the threshold and a millennium or more for temperatures a few degrees above the threshold). If the surrounding temperatures decline before the ice sheet is eliminated, the ice sheet might regrow." (1170) In thinking about tipping points for the GIS, it would be more accurate (although still oversimplified) to consider a threshold regarding degree-years rather than degrees.

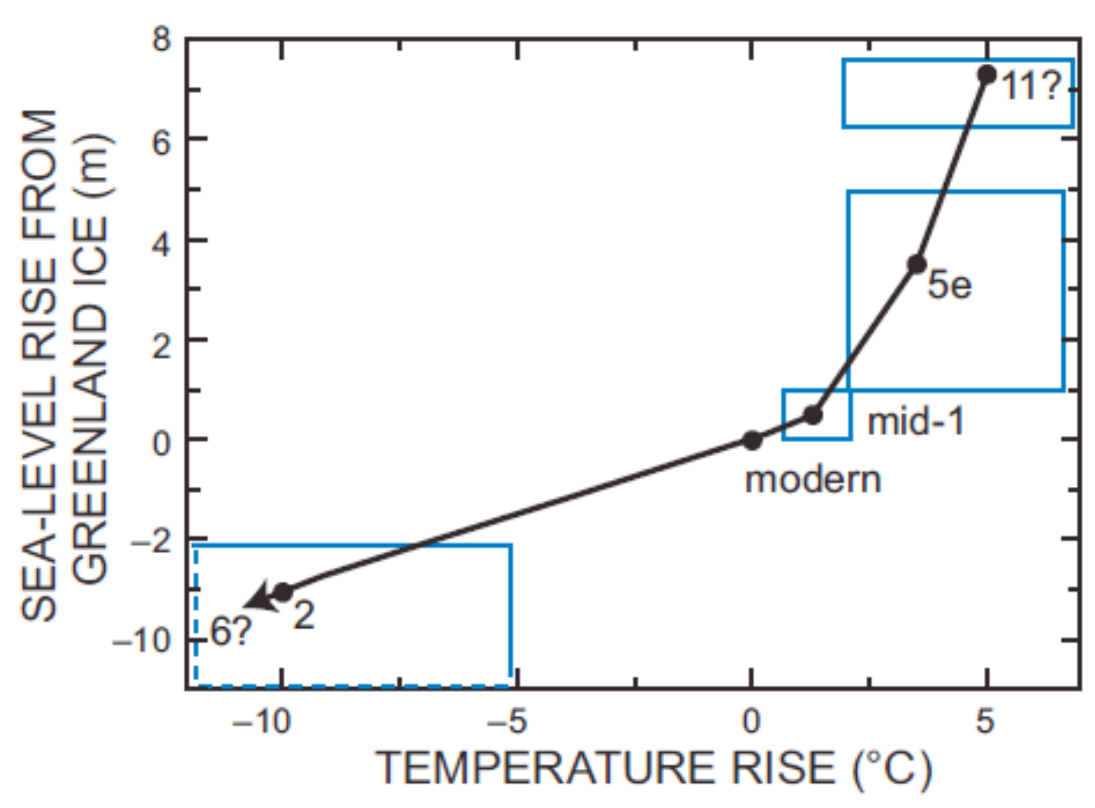

Figure 1. Estimated equilibrium temperature-volume relationship for the GIS

This figure summarizes the equilibrium relationship based on paleoclimatic findings. Note that the temperature is over the Greenland ice sheet. The standard conversion from average GIS temperature to global temperature is 1.5:1 for warming over the next century or so. Source: Alley et al. (2010), p. 23.

The first question involves the equilibrium temperature-volume relationship. The paleoclimatic history of the GIS was thoroughly reviewed in Alley et al. (2010). They summarize as follows

Paleoclimatic records show that the Greenland Ice Sheet consistently has lost mass in response to warming, and grown in response to cooling. [M] ajor changes of central regions of the ice sheet are thought to require centuries to millennia. The paleoclimatic record does not yet strongly constrain how rapidly a major shrinkage or nearly complete loss of the ice sheet could occur. The evidence suggests nearly total ice-sheet loss may result from warming of more than a few degrees above mean 20th-century values, but this threshold is poorly defined (perhaps as little as $2{ }^{\circ} \mathrm{C}$ or more than $7^{\circ} \mathrm{C}$ [in regional temperature]). 
In their summary of the paleoclimatic record, Alley et al. provide an equilibrium relationship between SLRe and temperature, shown in Figure 1. Note that the temperature in Figure 1 is on the ice sheet, and to get the global temperature would require dividing by 1.5. At temperatures around those of recent centuries, the GIS has an equilibrium volume close to the current level of $7.2 \mathrm{~m}$ of SLRe. Furthermore, at temperatures of 5 to $6{ }^{\circ} \mathrm{C}$ regional above current levels, or 3 to $4{ }^{\circ} \mathrm{C}$ global mean temperature, the ice sheet will eventually be completely or nearly completely melted. Figure 1 seems the most reliable estimate of the equilibrium relationship based on historical observations.

Ridley et al. (2010) examine the question of whether there are multiple stable states (see Figure 2). They do this by simulating the long-run dynamics of the GIS with preindustrial forcings and different starting points from $0 \%$ to $100 \%$ of current volume. They find that the ice sheet volumes eventually converge towards three stable equilibrium states at about $100 \%, 80 \%$, and $20 \%$ of present-day volume (V0). There are presumably two unstable points; one is around $90 \%$ of $\mathrm{V} 0$, and that is the divide between the $80 \%$ and $100 \%$ of $\mathrm{V} 0$. The other unstable point is around $50 \%$ of $\mathrm{V} 0$, which is the divide between $20 \%$ and $80 \%$ of V0. At $6^{\circ} \mathrm{C}$ increase in global mean temperature, the median time to the $90 \%$ instability threshold is 430 years in their modeling.

Similarly, a study by Robinson et al. (2012) examines the stability properties of the GIS for different temperature trajectories. They find hysteretic dynamics with multiple equilibria as shown in Figure 3 and its legend. There are three stable equilibrium paths traced out, the top and bottom solid lines and the middle dashed line. The points E1, E2, and E3 indicate three stable equilibria. At $1{ }^{\circ} \mathrm{C}$ warming, there are stable equilibria at $95 \%, 60 \%$, and $15 \%$ of current volume. As in many other studies, a small residual ice sheet (about $10 \%$ of V0) remains even with high temperatures. Transient experiments indicate that at a 6 ${ }^{\circ} \mathrm{C}$ increase, the $90 \%$ threshold is reached in around 450 years, consistent with the Ridley et al. (2010) estimate.

According to Robinson et al., the tipping points, or volumes that separate the long-run equilibria, will depend upon the temperature. At a global temperature of $1{ }^{\circ} \mathrm{C}$, the separation point between the upper and middle equilibria is $80 \%$ of current volume, while the separating point between the middle and lower equilibria is about $40 \%$. At low temperatures $\left(<1 / 2{ }^{\circ} \mathrm{C}\right)$, all considered paths go to the upper equilibrium eventually, while at high temperatures $\left(>2{ }^{\circ} \mathrm{C}\right)$, all paths eventually go to the lower equilibrium. 


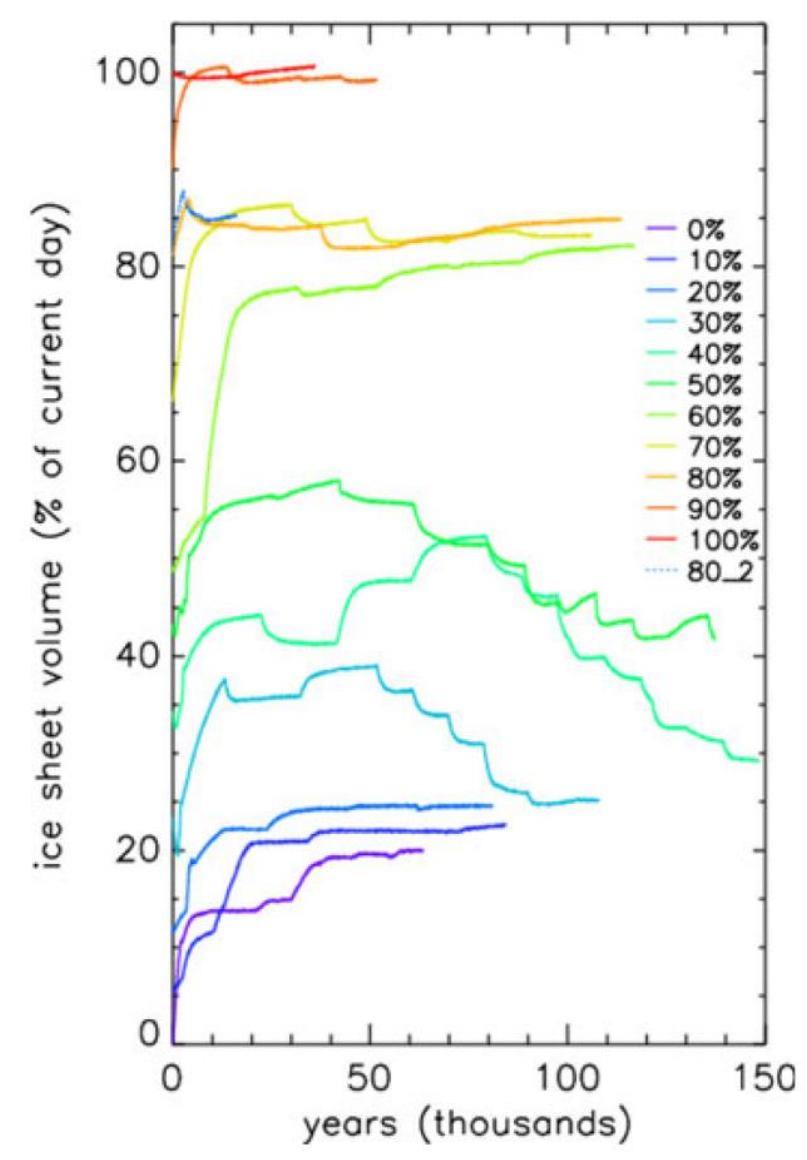

\section{Figure 2. Long-run instability}

This simulation calculates trajectories of ice-sheet volumes from different initial states toward the final equilibrium. Each simulation assumes preindustrial greenhouse-gas concentrations. The paths show the approach to icesheet equilibrium. The figure suggests convergence toward three equilibrium states, at about 100, 80, and 20\% of present-day volume. (Ridley et al., 2010, p. 1068)

At first blush, the GIS appears to be a clear example of a threshold that justifies the $2{ }^{\circ} \mathrm{C}$ ceiling for global temperature. However, here is where the integrated analysis of economics and geosciences becomes essential. Disintegration does not inevitably occur once the temperature threshold is passed. Rather, rapid and near-irreversible disintegration occurs only if a volumetric threshold is passed. A high-temperature path might well reduce the size of the GIS over, say, the next two centuries. However, as long as the GIS volume is above the volumetric threshold (say $80 \%$ of current volume), then reducing temperature back below the threshold will avoid passing the tipping point and prevent catastrophic flooding. 


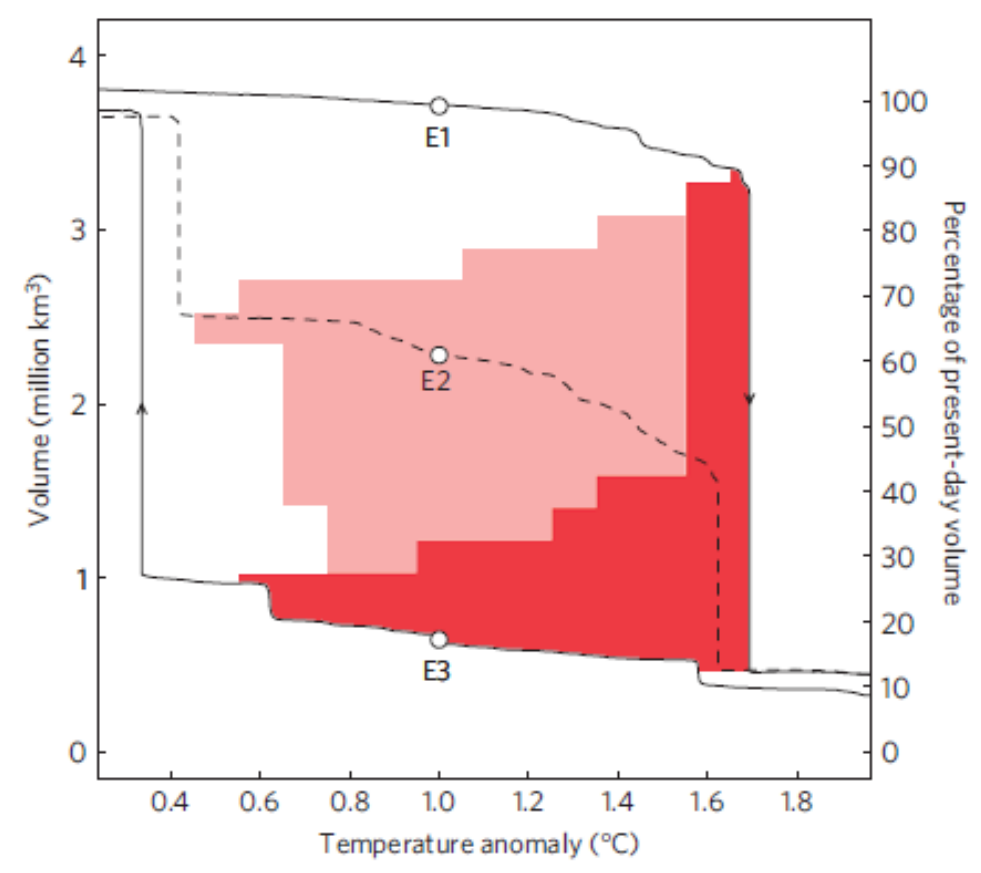

Figure 3. Equilibrium stability diagram of the GIS

The solid-line upper branch shows the GIS volume as the temperature increases, starting from the complete ice sheet (V0); the lower branch shows the volume as the temperature decreases, starting from ice-free conditions. The intermediate dashed line is a stable intermediate equilibrium. The shading shows the modeled basins of attraction in the multi-stable region. (Robinson et al. 2012, p. 430)

\section{Comparative Results of Alternative Ice Sheet Dynamics}

The paleoclimatic data do not yet provide a clear record for estimating the transient response of the GIS to different temperature trajectories.

Understanding dynamics relies on ice-sheet modeling.

A warning is in order, however, that current models give highly divergent estimates of the transient response to warming. For example, Bindschadler et al. (2013) experimented for 500 years with seven ice-sheet models. For the highest temperature path, the mean SLRe increase after 500 years was $72 \mathrm{~cm}$, but the range was $9-143 \mathrm{~cm}$. One concern is therefore that existing ice-sheet models cannot precisely resolve the transient path associated with climate change.

As background, I examined the paths in several studies of GIS dynamics. Most studies take a trajectory for global or GIS warming and then track the icesheet volume. A convenient way of summarizing the results is the melt rate per unit time per unit warming (in $\mathrm{cm} /$ century $/{ }^{\circ} \mathrm{C}$ ). The results of the comparison 
are shown in Figure 4. (For this discussion, the term "melt rate" is shorthand for the rate of decline of GIS volume.) ${ }^{2}$

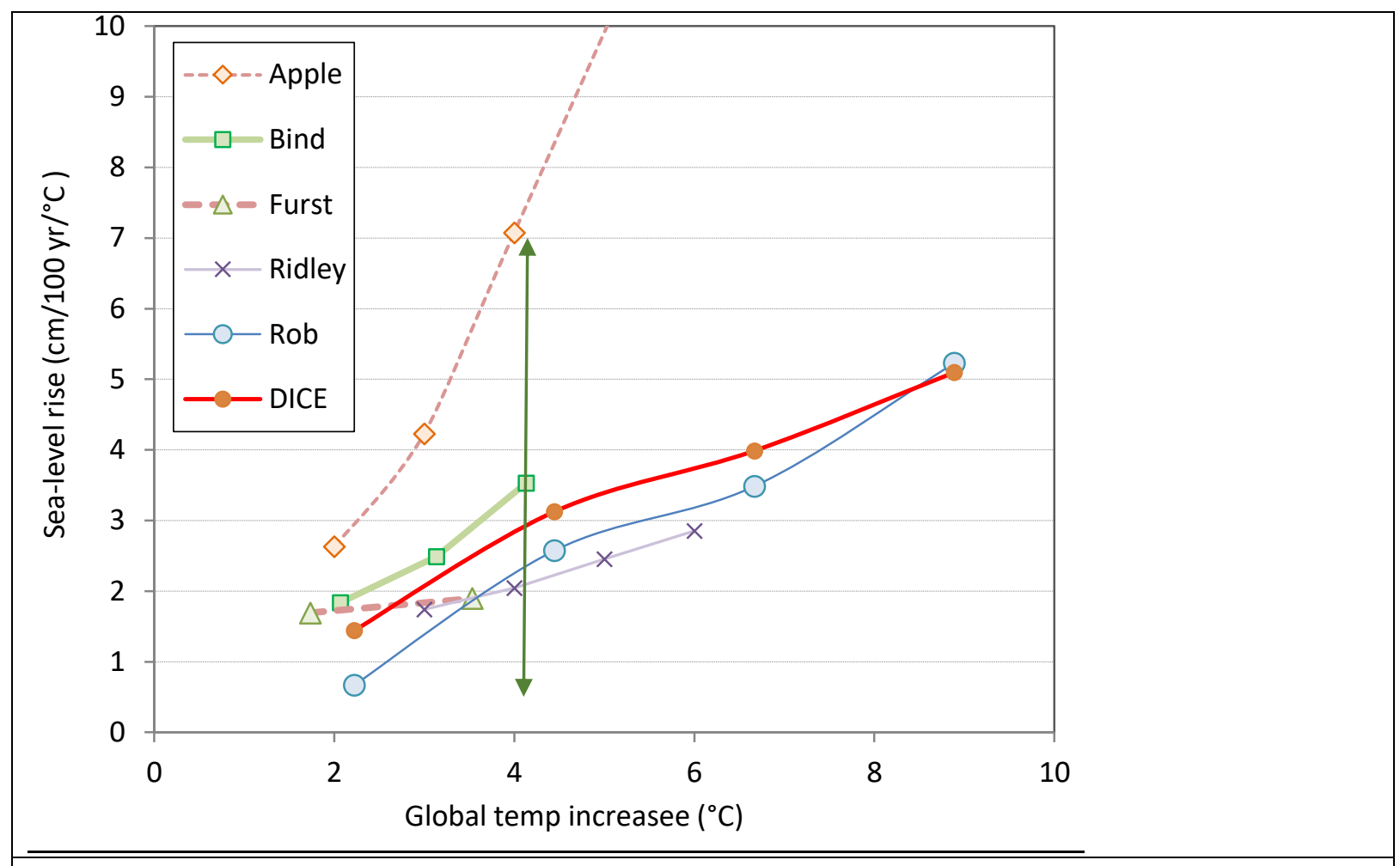

Figure 4. Alternative estimates of initial melt rate from different studies Estimates are provided in appendices $\mathrm{A}$ and $\mathrm{C}$. The arrow shows the range of studies for the Bindschadler et al. model-comparison study for the 500-year horizon and scenario C1. DICE is the results of the GIS estimates in the DICEGIS model.

[Legend: "Apple" = Applegate et al. (2014); "Bind" = Bindschadler et al. (2013); "Furst" = Furst et al. (2015); "Ridley" = Ridley et al. (2010); “Rob" = Robinson et al. (2012). The plot omits the high estimate from the Applegate et al. study.i]

For calibration purposes, the DICE-GIS relies on the results from Robinson et al. (2012), where the volume projections at different temperatures are shown in Figure 5. The advantage of relying on this simulation is that the numerical results are available, and it has a wide range of temperatures as well

2 There are many reasons for the model differences, such as the way that warming in the form of positive degree-days enters the model, the higher-order treatment of dynamics, and the use of the shallow-ice approximation in some but not all models. The SICOPOLIS model (which is widely used) is close to the model median in Bindschadler, and this is the model that I rely on in the calibration below. 
as a long simulation period. The calibration was primarily at high temperatures, as is seen in Figure 4. The model comparison study (Bindschadler et al. 2013) has a slightly higher average melt rate than Robinson, while the other three studies bracket Robinson.

\section{Modeling the Greenland Ice Sheet for Inclusion in Integrated Assessment Models}

\section{General considerations}

Ice-sheet models are highly complex as they require not only representations of the surrounding air and ocean temperatures but also, in the complete form, a three-dimensional model of the dynamics of the ice sheet. The studies shown in Figure 4 link climate models with ice sheet models (ISMs). Such models allow changes in climate simulated by the climate models to interact with the ISM through surface mass balance (SMB) feedbacks. The feedbacks include changes in surface albedo and elevation, circulation changes induced by topographical change, and changes caused by changes in freshwater runoff.

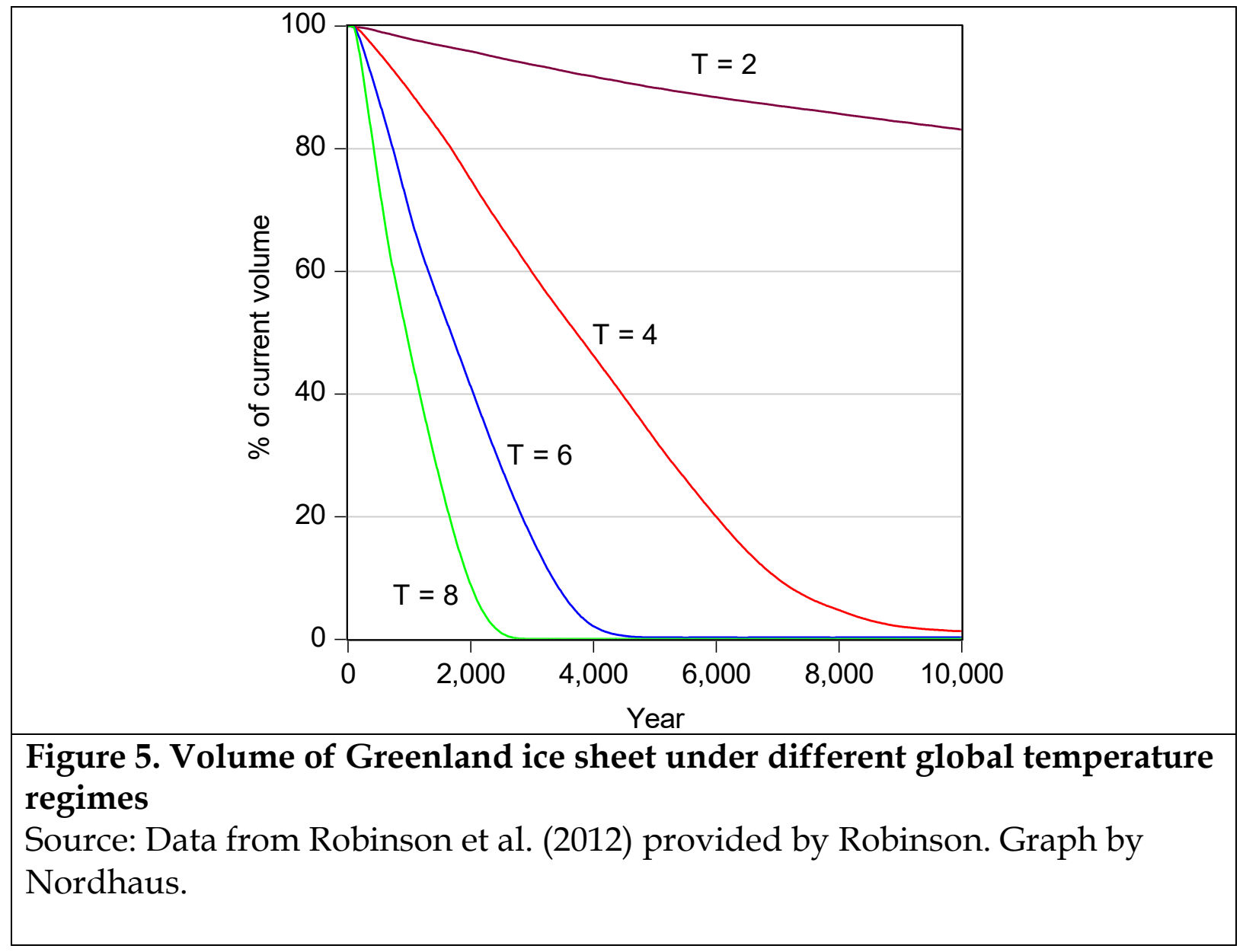


Since the modeling here relies on Robinson et al. (2012), that study's methods will be briefly described. The study starts with global climate models, which produce near-surface temperature anomalies prescribed over the boundary ocean points near Greenland. A regional energy-moisture balance model (REMBO) then takes the boundary conditions as well as the outputs of the ISM to simulate daily temperature and precipitation as well as surface mass balance (SMB), snowpack thickness, and albedo. The REMBO outputs are inputs to SICOPOLIS, which is a widely used three-dimensional, polythermal shallowice approximation ice-sheet model. The relevant outputs of REMBO are SMB and surface temperature, which are inputs to SICOPOLIS; changes in topography and ice-sheet extent calculated by the ice-sheet model are the output of SICOPOLIS and inputs to REMBO. The climate and SMB are updated every ten ice-sheet-model-years to provide accurate surface forcings to the ice sheet. Note that because REMBO is coupled to SICOPOLIS, the approach explicitly captures elevation and albedo feedbacks in the climate ice-sheet system at relatively high resolution ( $20 \mathrm{~km}$ grid).

It is important to understand how the albedo-altitude feedback leads to instability. Warming will reduce the elevation of the ice sheet, which will lead to higher temperatures at the top of the ice sheet. Additionally, a warmer ice sheet will have less snow cover, reducing the albedo and adding further heat. For example, snow has an assumed albedo of as high as 0.8 , while ice-free land has an assumed albedo of 0.2 . Therefore, while only $20 \%$ of solar radiation would be absorbed by a cold ice sheet covered with snow, $80 \%$ of radiation would be absorbed by ice-free land. It is easily seen how this feedback could lead to continued deglaciation. The offset to this factor, it turns out, is the positive association of temperature and precipitation, which can offset some or all of the albedo-elevation feedback.

\section{Modeling details}

The strategy in developing the DICE-GIS model is to incorporate a simplified representation of more complex GIS models. The following presents a small structural dynamic model that allows for any of the three types of dynamics (reversible, hysteretic, and irreversible). It is small, can be calibrated to larger realistic models, and can be incorporated into integrated assessment models.

The basic equations are as follows: Begin with an equilibrium relationship between temperature $\left(\mathrm{T}^{*}\right)$ and ice-sheet volume $\left(\mathrm{V}^{*}\right)$ :

$$
\text { (1) } \quad T^{*}=f\left(V^{*}\right)
$$

The equation is written in this form because there is a unique temperature for each volume. In the central specification used in this study, the inverse function 
is one-to-one. However, in other specifications, such as one displaying hysteresis discussed in a later section, the inverse function does not hold uniquely (that is, there may be multiple equilibrium volumes associated with a single temperature, as shown in Figure 2).

Figure 6 shows three alternative versions of equation (1). Figure $6 a$ is a completely reversible dynamic system such as shown in Figure 1, where the ice sheet marches down the $f\left(V^{*}\right)$ curve in a warming world, and then marches back up the same curve as temperatures fall. Figure $6 \mathrm{~b}$ is the hysteresis diagram such as is shown in Figure 2. Note that the irreversible case is at one extreme of the hysteresis curve, while the reversible case is at the other pole where the two branches in $6 \mathrm{~b}$ collapse into one branch.

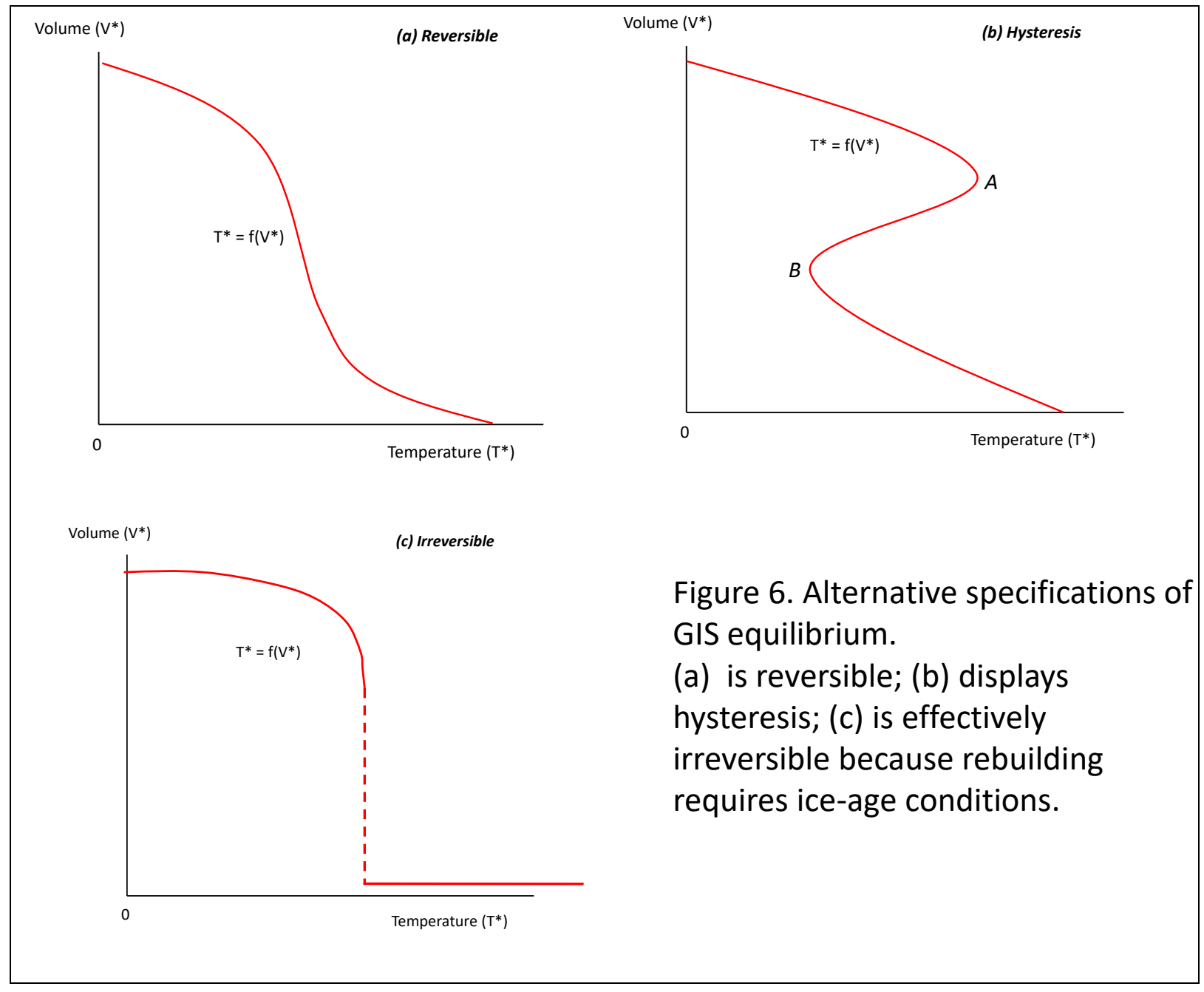

For most dynamic systems with two stable equilibria, as shown in Figures 6 and simulated below, there will also be one unstable equilibrium. The upper equilibrium will be traced out as the GIS melts, and the lower equilibrium will be traced out as the GIS rebuilds. The unstable middle curve between $A$ and $B$ in Figure $6 \mathrm{~b}$ will not be observed. ${ }^{\text {ii }}$ 
The next question involves the dynamics of volume adjustment. The simplest relationship is a differential equation (discretized in practice) in which the volume adjusts as a function of actual and equilibrium temperature and actual volume. ${ }^{3}$

$$
\frac{\partial V(t)}{\partial t}=g\left[T(t), T^{*}(t), V(t)\right]
$$

The present study focuses primarily on the completely reversible system, shown in Figure 6a. It also assumes that the equilibrium function is linear to simplify the analysis. The dynamic equation for the linear model is estimated from Robinson's simulations using the data shown in Figure 5 (see Appendix B for the results). The final equations are the following:

$$
\begin{aligned}
& T^{*}(t)=3.4[1-V(t) / 100]^{2} \\
& \frac{\partial V(t)}{\partial t}=-0.0053 \operatorname{sgn}\left[T(t)-T^{*}(t)\right]\left[T(t)-T^{*}(t)\right]^{2}[V(t) / 100]^{0.2}
\end{aligned}
$$

Here, $V^{*}(t)$ and $T^{*}(t)$ are equilibrium volumes and temperature, while $T(t)$ and $V(t)$ are actual values. Equation (3) takes the paleoclimatic equilibrium shown in Figure 1 above and linearizes the relationship between the modern era and the interglacial period. Note that the coefficient $\left(3.4^{\circ} \mathrm{C}\right)$ is the difference between the global interglacial temperature and the global glacial maximum temperature. At full volume $(V=100 \%)$, the equilibrium temperature is $0{ }^{\circ} \mathrm{C}$, while the GIS fully melts in equilibrium at $3.4^{\circ} \mathrm{C}$ global above pre-industrial levels.

Equation (4) is the melt-rate equation. The first term is the coefficient determined from a regression analysis. The second term introduces the sign of the temperature difference. The temperature difference enters as a squared function. The last term, $[V(t) / 100]^{0.2}$, ensures that volume is positive. To take an example, at an initial volume of $100 \%$ and a global temperature of $6{ }^{\circ} \mathrm{C}$, the icesheet decline is $0.19 \%$ per five years, or $28 \mathrm{~cm}$ of SLRe per century. If the actual temperature is less than equilibrium, the ice sheet rebuilds.

Figure 7 and Table 1, as well as Figures B-1 and B-2 in Appendix B, show a comparison of the Robinson et al. model runs with those of the DICE-GIS. The Robinson calculation declines more slowly at the beginning, but the two models have similar long-run trajectories. The differences between the Robinson and

${ }^{3}$ An alternative used in Bakker et al. (2016) uses quadratic functions in temperature for both the adjustment and the equilibrium. This approach was tested against the Robinson data and has a significantly poorer statistical fit than equations (3) and (4). 
DICE runs are small relative to the differences among ice-sheet models shown in Figure 4.

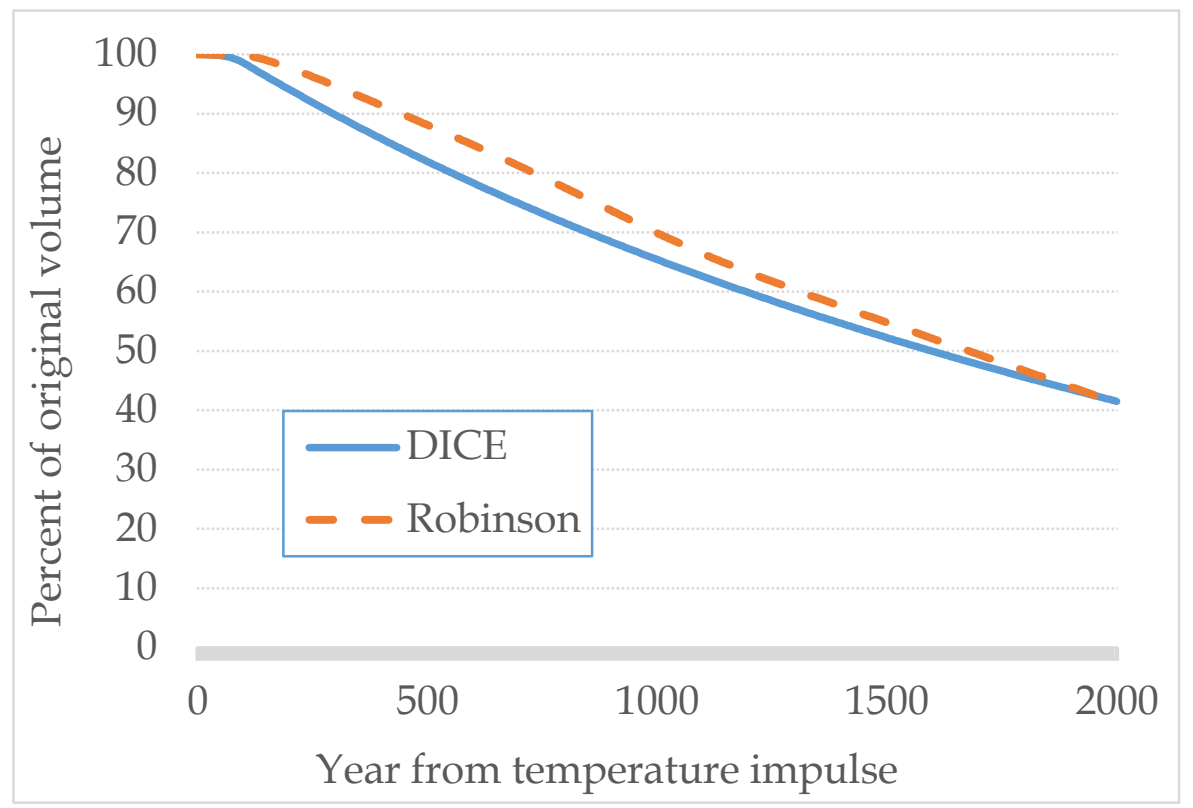

Figure 7. GIS model comparisons

Comparison of DICE reduced-form model and Robinson calculation for a global temperature increase of $6.7^{\circ} \mathrm{C}$. iii

\begin{tabular}{||c|c|c|r|r|r|r|r|r||}
\hline & DICE & Robinson & DICE & Robinson & DICE & Robinson & DICE & Robinson \\
\cline { 2 - 9 } Year & $\mathrm{T}=2.2$ & $\mathrm{~T}=2.2$ & $\mathrm{~T}=4.4$ & $\mathrm{~T}=4.4$ & $\mathrm{~T}=6.7$ & $\mathrm{~T}=6.7$ & $\mathrm{~T}=8.9$ & $\mathrm{~T}=8.9$ \\
\hline 100 & 99.84 & 99.87 & 98.14 & 99.85 & 98.56 & 99.84 & 97.45 & 99.74 \\
200 & 99.32 & 99.75 & 96.15 & 99.16 & 94.06 & 97.70 & 89.57 & 94.93 \\
500 & 97.82 & 99.12 & 90.56 & 95.72 & 81.94 & 88.10 & 69.22 & 74.59 \\
1000 & 95.48 & 97.90 & 82.40 & 89.44 & 65.41 & 69.88 & 43.44 & 47.70 \\
1500 & 93.32 & 96.82 & 75.38 & 82.66 & 52.24 & 54.77 & 24.65 & 25.98 \\
2000 & 91.32 & 95.86 & 69.29 & 74.95 & 41.52 & 41.23 & 10.83 & 8.88 \\
3000 & 87.71 & 93.68 & 59.20 & 59.85 & 25.20 & 16.48 & 0.10 & 0.09 \\
\hline
\end{tabular}

Table 1. Results of DICE and Robinson calculations for different temperature trajectories and time periods.

Each pair of numbers compares the calculations from the DICE-GIS model with the Robinson calculations. The temperatures are ${ }^{\circ} \mathrm{C}$ global. 


\section{V. $\quad$ Model Structure}

The DICE-GIS model is a straightforward integration of the GIS model discussed in the last section with the DICE-2016R2 model. ${ }^{4} \mathrm{~A}$ few changes have been introduced into the standard DICE model to reflect the long time period. The full set of variables and equations for the GIS addition are provided in Appendices D and E.

The new assumptions in the standard DICE module are the following. First, no negative emissions are allowed past 2200. If these are allowed, then the optimal solution is to run atmospheric carbon concentrations low enough that the GIS stays at current volume. Second, the rate of decarbonization is set at zero after 2200. Without this assumption, emissions go quickly to zero. Third, several parameters are set as constants after 2200 for computational stability. These include the savings rate and the rate of productivity growth. The runs are for 1500 years.

The following list shows the scenarios used for the present study.

1. Discounting. Because of the long time lags, disintegration has a small impact on policy under normal discounting. The simplest way to deal with this concern is to consider as well low discount rate. This approach is consistent with other studies that advocate low discounting to reflect major losses in the distant future.

2. Damages on SLR. A second assumption concerns the damages from sealevel rise. The present study takes the results of Diaz (2016). This study finds that SLR of 0.8 meters in 2100 has an impact of $1.5 \%$ of global output without adaptation and $0.18 \%$ of output with adaptation. This study takes the intermediate estimate of $1 \%$ of global output lost for each 1 meter of SLR. The damage function is linear in SLR in light of findings from Diaz. This function implies that complete disintegration of the GIS would lead to $\approx 7 \%$ loss in global income each year. Note that if modeling takes the constrained volume approach in \#4b, the GIS component of damages is omitted.

3. Alternative melt rates. The standard melt rate (or more precisely, GIS volume change) has been discussed above. For sensitivity analyses, I assume a melt rate two times the calibrated level. This takes the melt rate beyond any of the estimates that have been included in the IPCC Fifth Assessment Report (2013) but is useful for analytical purposes.

4 The latest version of the DICE-2016R2 model is available at http://www.econ.yale.edu/ nordhaus/homepage/homepage/DICE2016R091916ap.gms. 
4. Economic calculations. There are two alternative methods of treating the economic impact of the disintegration of the GIS.

a. Damage function approach. The first is to modify the damage function to include damages as described above.

b. Constrained volume approach. A second approach is to constrain the GIS volume to be above a given threshold. For example, GIS volume might be constrained above $90 \%$ of its original volume. The volumetric approach is useful if estimates of GIS damages are imprecise, if the damage-function approach is unacceptable, or if it is desired to avoid tipping points in the ice-sheet dynamics.

This list provides a large array of potential strategies for including the GIS in integrated assessment models. Another set of issues is the potential for irreversibility and hysteresis, whose dynamics are examined in later sections.

\section{Results for the DICE-GIS Model}

\section{Baseline results}

Begin with the results of the standard DICE model with the new GIS module added. Figure 8 shows the trajectory of GIS volume for three cases: an optimal climate policy; a baseline of no climate policy; and a baseline policy followed by geo-engineering after 500 years.

The results are straightforward. With standard damages, discounting, and melt rate, the baseline path has the GIS disintegrating gradually over the coming centuries. By contrast, the optimal path has a much slower decline, staying above the upper tipping point of $80 \%$ volume.

Figure 8 also shows the result of a geo-engineering experiment. This run assumes that a geo-engineering technology reduces the temperature over the GIS to $0{ }^{\circ} \mathrm{C}$ at year 500 into the run. The GIS model used here suggests that there is little rebuilding of the GIS from the geo-engineering, but the decline does stop. This point is further analyzed in section $\mathrm{D}$ below. The arrow in Figure 8 shows IPCC estimates of the impact of baseline radiative forcings on the GIS at 500 years for different ice-sheet models.

It is useful to compare the social cost of carbon for three cases: normal damages, GIS damages only, and combined damages. Table 2 shows the components. For completeness, this also shows the results for low discounting ( $1 \%$ per year). These calculations suggest that the damages associated with GIS disintegration are a small fraction of the total damages. GIS damages are $0.4 \%$ of the total at normal discounting and $1.8 \%$ with low discounting. 
Table 2 is relevant for the question of whether current estimates of the social cost of carbon underestimate the "true" SCC because of omissions of major tipping points such as the GIS. While the GIS is but one of the potential omissions in current methods, the baseline and low-discounting calculations suggest that the GIS omission is somewhere between negligible and small.

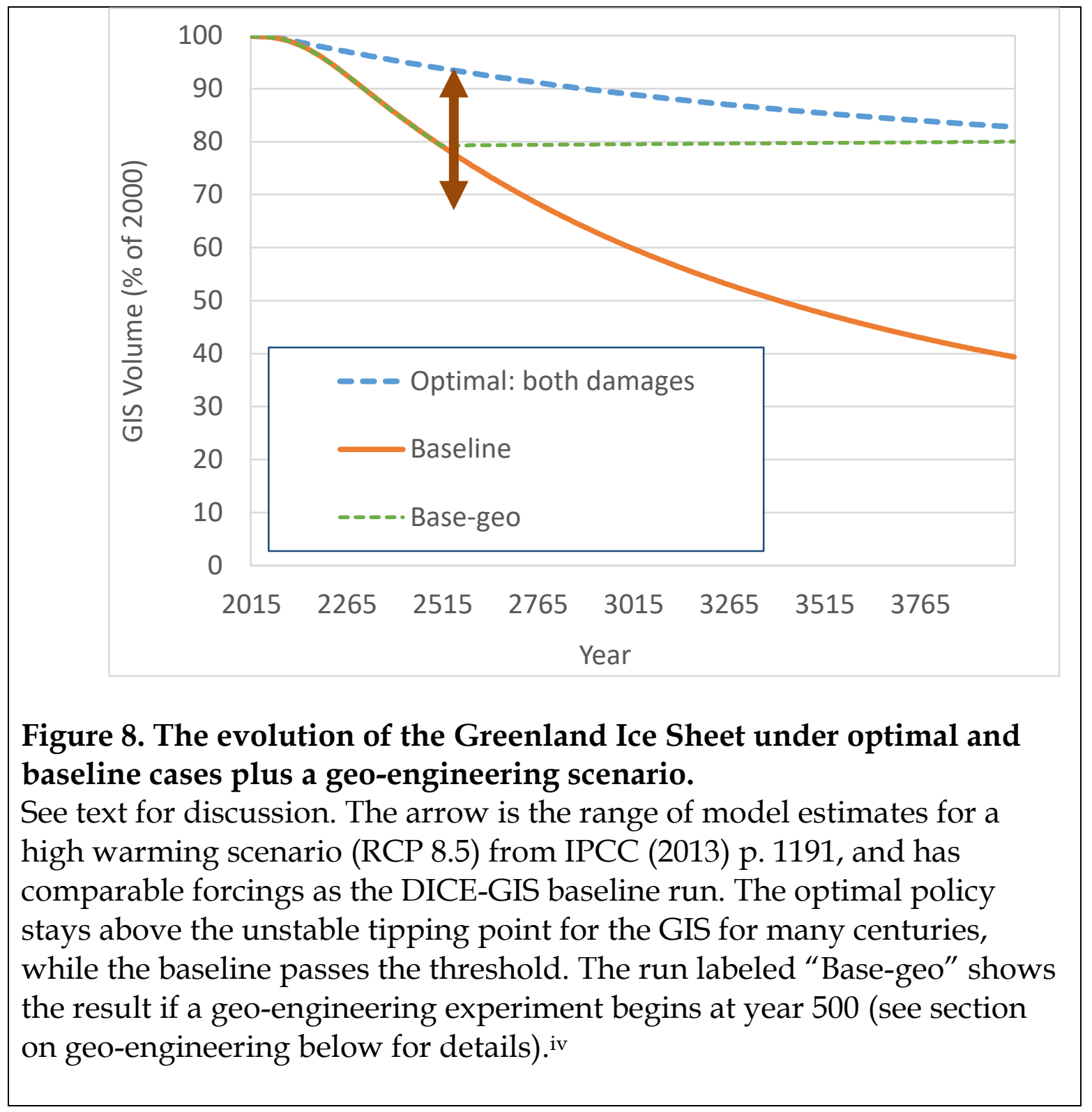

\section{Impact of discounting}

The question of the appropriate discount rate is a deep and unsettled one. The standard DICE model uses a discount rate on goods that is calibrated to the rate of return on capital. Alternatives proposed by scholars, such as in the Stern Review (2005), use a lower discount rate that is based on intergenerational neutrality. While there are strong arguments on both sides, it is useful to determine the impact of different discount rates on the optimal climate 
trajectory. The easiest way to implement alternatives is to assume different constant discount rates, here $0.1 \%, 1 \%, 2 \%, 3 \%, 4 \%$, and $5 \%$ per year. The lower two rates raise economic issues because the discount rate is lower than the growth of output for two centuries. Because of numerical problems, the model with low discount rates does not converge for periods longer than 2000 years.

Table 3 shows the results for different discount rates and two alternative melt rates. The first two columns show the SCC for the GIS only and the SCC for all damages. As is well known, the SCC rises sharply as the discount rate falls.

The more interesting feature is the relationship between the SCC with and without GIS damages, shown in the last column of Table 3. This ratio is virtually zero for relatively high discount rates ( $3 \%$ and above) and the standard melt rate. For the lowest discount rates and the higher melt rate, the ratio of the SCC with only GIS damage to that with all damages rises to $5 \%$ of the total. In all cases examined, the GIS adds little to the SCC.

\begin{tabular}{|l|r|r|r|r|}
\hline \multirow{2}{*}{ Scenario } & \multicolumn{2}{|c|}{ SCC, 2015 (2011\$/tCO2) } & \multicolumn{1}{|c|}{ Percent of total SCC } \\
\cline { 2 - 5 } & $\begin{array}{c}\text { Base } \\
\text { discounting }\end{array}$ & $\begin{array}{c}\text { Low } \\
\text { discounting }\end{array}$ & $\begin{array}{c}\text { Base } \\
\text { discounting }\end{array}$ & $\begin{array}{c}\text { Low } \\
\text { discounting }\end{array}$ \\
\hline Both damages & 31.39 & 1,191 & & \\
Normal damages only & 31.23 & 1,172 & $99.6 \%$ & $98.2 \%$ \\
GIS damages only & 0.13 & 21 & $0.4 \%$ & $1.8 \%$ \\
Sum of two individual & 31.36 & 1,193 & & \\
\hline \multicolumn{5}{|c|}{} \\
Table 2. Social cost of carbon for standard and low discounting. \\
Note that GIS damages are a small percent of the total, although larger for low \\
discounting. These calculations use a 1000-year time horizon, but using a \\
2000-year horizon makes little difference. \\
\hline
\end{tabular}

\section{Volume constraints}

Estimates of the damage from sea-level rise due to GIS melt are highly uncertain. The damage estimate used in the modeling assumes limited adaptation, whereas high adaptation would produce about one-fifth of the damages based on the Diaz (2016) study.

An alternative approach is to limit the decline in the volume of the GIS. A natural set of limits would use the thresholds that have been suggested by current research. Ridley et al. (2010), as shown in Figure 2, has tipping points at 
$10 \%, 50 \%$, and $90 \%$ of current volume. These are thresholds for a global temperature of $0{ }^{\circ} \mathrm{C}$. Analogous experiments by Robinson et al. also find three stable equilibria and two tipping points. The present calculations use the Ridley et al. (2010) thresholds to constrain the GIS volume above 10, 50, and 90\% of current volume.

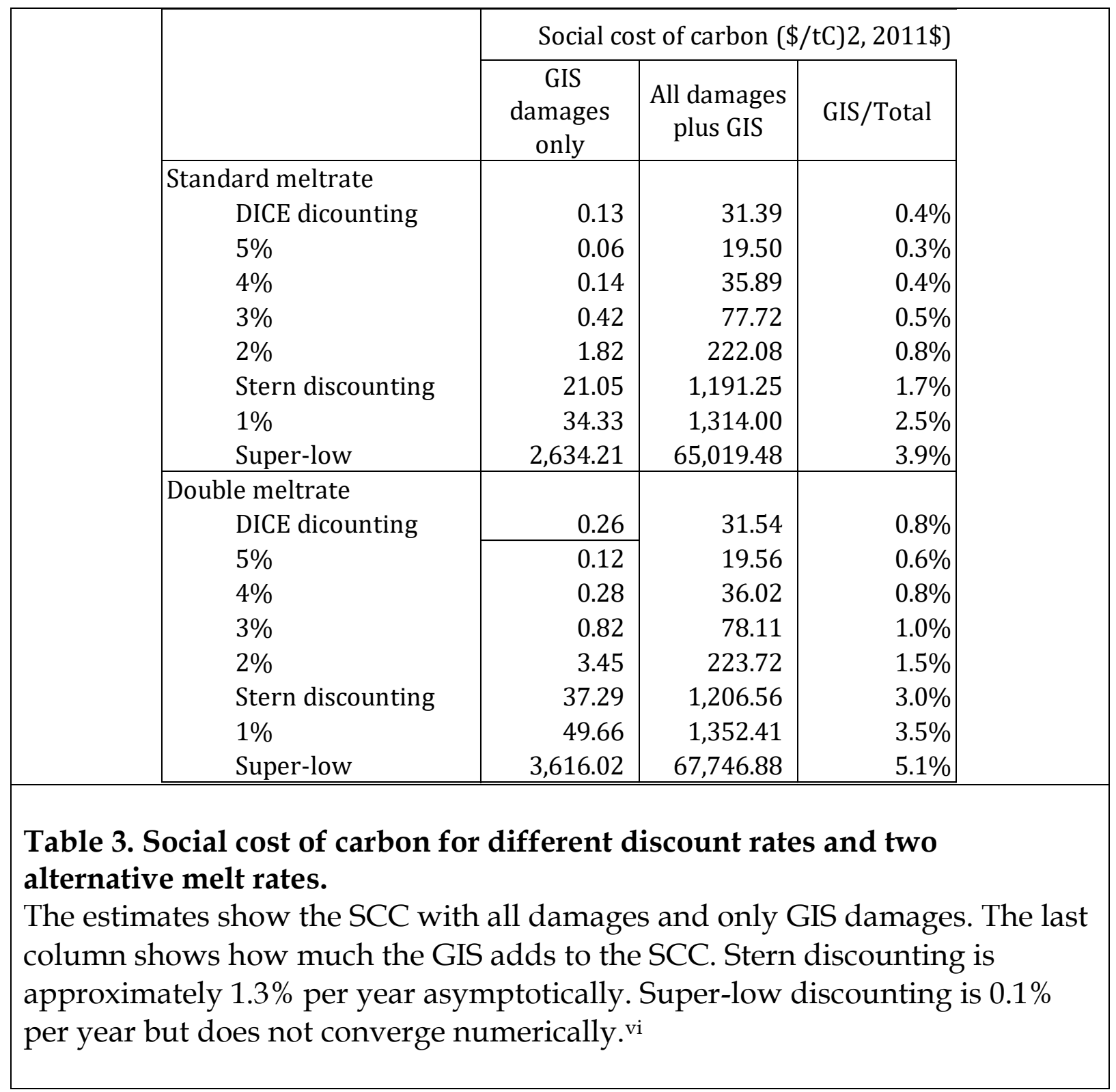

Table 4 shows the results of the volumetric approach. These estimates show DICE discounting, the 3\% discount rate used by the US government, and the low discount rate of $1 \%$ per year. The runs are optimized and include normal damages. However, GIS economic damages are removed and replaced by the volumetric constraint. 


\begin{tabular}{|c|c|c|c|c|c|c|}
\hline \multicolumn{3}{|c|}{ Parametric specification } & \multicolumn{3}{|c|}{ Social cost of carbon, 2015 (2011\$/t CO2) } & \\
\hline $\begin{array}{l}\text { Discount } \\
\text { rate }\end{array}$ & Melt rate & $\begin{array}{c}\text { Volume } \\
\text { lower limit } \\
\text { (\% of } \\
\text { current) } \\
\end{array}$ & $\begin{array}{l}\text { Volume } \\
\text { limited }\end{array}$ & $\begin{array}{l}\text { Damage } \\
\text { function }\end{array}$ & $\begin{array}{l}\text { Ratio: Volume } \\
\text { lim/Damage fn }\end{array}$ & \\
\hline DICE & $1 \mathrm{X}$ & 10 & 30.69 & 30.84 & 0.995 & \\
\hline $3 \%$ & $1 \mathrm{X}$ & 10 & 78.16 & 78.56 & 0.995 & \\
\hline $1 \%$ & $1 \mathrm{X}$ & 10 & 972.82 & 991.96 & 0.981 & \\
\hline DICE & $2 \mathrm{X}$ & 10 & 30.69 & 30.98 & 0.991 & \\
\hline $3 \%$ & $2 \mathrm{X}$ & 10 & 78.16 & 78.95 & 0.990 & \\
\hline $1 \%$ & $2 \mathrm{X}$ & 10 & 973.00 & $1,010.24$ & 0.963 & \\
\hline DICE & $1 \mathrm{X}$ & 50 & 30.69 & 30.84 & 0.995 & \\
\hline $3 \%$ & $1 \mathrm{X}$ & 50 & 78.16 & 78.56 & 0.995 & \\
\hline $1 \%$ & $1 \mathrm{X}$ & 50 & 972.82 & 991.96 & 0.981 & \\
\hline DICE & $2 \mathrm{X}$ & 50 & 30.69 & 30.98 & 0.991 & \\
\hline $3 \%$ & $2 \mathrm{X}$ & 50 & 78.16 & 78.95 & 0.990 & \\
\hline $1 \%$ & $2 \mathrm{X}$ & 50 & 973.00 & $1,010.24$ & 0.963 & \\
\hline DICE & $1 \mathrm{X}$ & 90 & 39.41 & 30.84 & 1.278 & \\
\hline $3 \%$ & $1 \mathrm{X}$ & 90 & 83.59 & 78.56 & 1.064 & \\
\hline $1 \%$ & $1 \mathrm{X}$ & 90 & 972.82 & 991.96 & 0.981 & \\
\hline DICE & $2 \mathrm{X}$ & 90 & 85.12 & 30.98 & 2.748 & \\
\hline $3 \%$ & $2 X$ & 90 & 138.27 & 78.95 & 1.751 & \\
\hline $1 \%$ & $2 \mathrm{X}$ & 90 & 973.00 & $1,010.24$ & 0.963 & \\
\hline \multicolumn{7}{|c|}{$\begin{array}{l}\text { Table 4. Comparison of optimal policy under both volumetric constraints } \\
\text { and damage function. } \\
\text { For the calculations with "volume limited," the DICE-GIS model is run } \\
\text { constraining volume to be above three tipping volumes. The paths are } \\
\text { optimized including standard damages but replace the assumed GIS damages } \\
\text { with the volumetric constraint. These are compared with the standard } \\
\text { calculations. The SCC is lower with the GIS volume constraint when it is not } \\
\text { binding. Four cases with shaded regions at the bottom are ones where the } 90 \% \\
\text { volume constraint is binding. The SCC is between } 6 \% \text { and } 175 \% \text { higher in } \\
\text { those cases. vii }\end{array}$} \\
\hline
\end{tabular}

For most cases, the volumetric constraint is not binding, and the SCC is slightly lower than the standard estimates in Table 3 . For the cases of the upper threshold ( $90 \%$ minimum) and the two higher discount rates, the volume constraint is binding, and the SCC is higher than the standard. With a $2 \mathrm{X}$ melt rate and a $90 \%$ volume constraint, the SCC is elevated and on the order of $\$ 100$ per ton of $\mathrm{CO}_{2}$.

The important result of imposing the volume constraint is that it requires a relatively high SCC to meet the tightest constraint of limiting to a $10 \%$ melt. 
For looser constraints, the appropriate SCC is little changed from the standard value.

\section{Geo-engineering to limit temperature}

A final set of experiments examines geo-engineering which reduces temperature to reverse the GIS disintegration. These experiments assume that global and GIS temperatures are reduced to $0{ }^{\circ} \mathrm{C}$ after a given year. The geoengineering might occur through radiation management (putting particles in the atmosphere) or carbon reduction (say through carbon-removal technologies).

In looking at these geo-engineering simulations, the striking result is that rebuilding the GIS is quantitatively different from disintegration. The asymmetry is seen in Figure 1, where the disequilibrium dynamics are very different in a melt mode from a rebuild mode.

The asymmetry can also be seen in the Applegate-Keller results shown in Figure 9. They run experiments with rapid warming followed by geoengineering at different times. In the experiment with a $6{ }^{\circ} \mathrm{C}$ increase in global temperature, the melt rate rises to approximately $13 \mathrm{~mm} / \mathrm{yr}$. However, when the temperature is reduced to $0{ }^{\circ} \mathrm{C}$, the ice sheet rebuilds at a rate of only 0.5 $\mathrm{mm} / \mathrm{yr}$. A similar pattern is seen in the hysteresis tests in Robinson et al. (2012), Figure SI-S4. This study has a scenario in which temperature is reduced to $0.4{ }^{\circ} \mathrm{C}$ starting from a volume of $20 \%$ of current levels. In the Robinson simulation, the ice sheet rebuilds to $70 \%$ of volume after 50,000 years. This result represents an increase of $0.07 \mathrm{~mm} / \mathrm{yr}$. The estimates in the Ridley et al. (2010) calculations in Figure 1 indicate a buildup of about $0.1 \mathrm{~mm} / \mathrm{yr}$ in the accumulation phase.

The geo-engineering experiments in DICE-GIS are roughly the same as the results from the three modeling studies. Consider a scenario in which GIS volume is reduced to $20 \%$ of current levels, at which time temperature is reduced to $0.4^{\circ} \mathrm{C}$. The rebuilding rate is around $0.25 \mathrm{~mm} /$ year in the DICE-GIS. A GIS temperature anomaly of $6{ }^{\circ} \mathrm{C}$ global for 300 years leads to approximately 2 meters of SLR at that time. If the temperature is reduced to zero in a geoengineering experiment, the GIS is estimated to rebuild by only 0.2 meters after 1000 years, or about $0.2 \mathrm{~mm} /$ year.

The reasons for the strong asymmetry may puzzle those outside of the geosciences. The asymmetry can be understood in a mathematical way and in a physical way. The mathematics involves the melt-rate function. We have estimated that the melt rate is a function of the squared difference between the actual and equilibrium temperature, that is $\partial V(t) / \partial t \sim\left(T(t)-T^{*}(t)\right)^{2}$. In the warm phase, the difference is large, perhaps $6^{\circ} \mathrm{C}$, so the melt rate is a constant times 36 . In the cooling phase, the equilibrium volume is close to the actual volume, so $T(t)-T^{*}(t)$ is small, perhaps 1 . So the melt rate would be about $1 / 36^{\text {th }}$ of the rate in the warm phase. 
The physics provides a different explanation. (I am grateful to Klaus Keller for this explanation.) An ice sheet melts when the temperature is elevated, and the decumulation (here meaning melting plus glacial discharge) exceeds accumulation (precipitation). However, there is no "negative melting" in the cold phase. Rather, to build an ice sheet requires not just cold temperatures, but also precipitation. The precipitation rate over the ice sheets is, however, quite small. So when the melting slows to close to zero, the net volume change is determined by precipitation minus glacial discharge. Since melting is a function of positive degree-days, positive degree days approach zero with cooling. This implies that there is a sharp asymmetry in the response of the ice sheet to positive and negative temperature shocks.

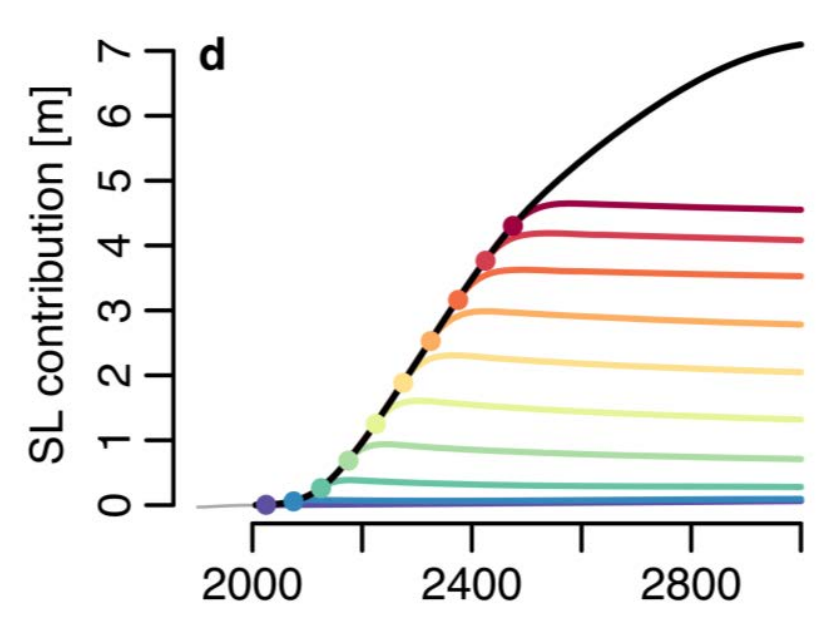

Figure 9. Sea-level rise with temperature increase and decrease

The horizontal lines show the decline in sea level during geo-engineering experiments in the SICOPOLIS model from Applegate and Keller (2015). The lines represent scenarios that reduce temperature to zero at different starting points from 2025 to 2475 . The key finding is the slow ice-sheet buildup during geo-engineering.

The conclusions of the geo-engineering simulations have important implications for climate policy. Moreover, the results apply to mitigation and carbon removal as well as solar-radiation management. They suggest that disintegration of the GIS is essentially irreversible on a relevant societal time scale. It might be that the GIS will rebuild, but to the extent that existing model calculations are accurate, the rebuilding is so slow that from an analytical perspective disintegration should be considered irreversible. This conclusion has the important reservation that it has not been validated in multiple model calculations, so it should be treated with caution. 


\section{Alternative Equilibrium Specifications: Non-linear, Irreversible, and}

$\underline{\text { Hysteretic }}$

The basic model analyzed here uses a linear relationship between equilibrium volume and temperature. This section considers alternative specifications of the equilibrium relationship: non-linear, irreversible, and hysteretic.

\section{Non-linear equilibrium function}

The first alternative is to assume that the equilibrium volume-temperature function is non-linear as shown by the finding from paleoclimatic studies and summarized in Figure 1. Figure 1 shows $V^{*}$ is a concave function of $T^{*}$. As noted above, the modeling needs to invert this to ensure uniqueness. This relationship

can be represented by a function of the form $T^{*}=3.4\left(1-V^{*} / 100\right)^{0.5}$. To maintain the same temperature-volume trajectory as the linear function for the first two centuries, the melt-rate coefficient is adjusted upward by about $10 \%$.

Calculations indicate that the optimal and baseline paths are virtually identical for the standard coefficients and discount rates. For example, the SCC associated with only GIS damages is $\$ 0.134$ per ton $\mathrm{CO}_{2}$ with the linear model and $\$ 0.133$ per ton $\mathrm{CO}_{2}$ with the non-linear model. Differences appear with low and super-low discount rates ( $1 \%$ and $0.1 \%$ per year). At these low rates, the ice sheet melts slightly more slowly with the non-linear specification than the linear specification. This leads to higher long-run volumes and a lower SCC with the non-linear equilibrium function.

So the conclusion on introducing a non-linear (concave) equilibrium temperature-volume relationship is that there are negligible changes in the near term with standard parameters, while long-run disintegration is slightly lower with the non-linear function. Numerical results are not presented as they are not interesting.viii

\section{Irreversible disintegration}

A second alternative structure assumes irreversible disintegration, as in Figure 6c. That is, once melted to a given volume, the ice sheet cannot rebuild. To begin with, this is both physically and historically unrealistic. Paleoclimatic data (such as reported in Figure 1) indicate a reversible pattern during ice ages and interglacial periods. Moreover, all models that allow for wide variations of forcings indicate changes from virtually ice-free to highly glaciated conditions.

On the other hand, as the experiments with geo-engineering indicate, the rebuilding of the GIS in a period of colder conditions is extremely slow. The pace of rebuilding is so slow, indeed, that from a societal vantage point, the dynamics can usefully be thought of as irreversible. 
A final observation is to examine the different runs for the linear model. In the baseline and optimal runs, none of the sixteen runs examined displays a rebuilding of the ice sheet. There might be situations where the path is rebuilt, but these do not appear in the DICE-GIS model.

All these results indicate that, for the modeling of the ice sheet used in the present study, there are no further implications of imposing irreversibility. The system is already so close to irreversible that adding complete irreversibility has no effect.

\section{Hysteresis in equilibrium temperature-volume relationship}

A final approach is to examine the implications of an ice sheet displaying hysteresis. To modify the model for this property, the equilibrium temperaturevolume relationship was assumed to follow a cubic function with the shape shown by the curved line in Figure 10 (for comparison, the linear relationship is shown as a dashed line). The hysteretic curve is generated to resemble the estimates in Robinson et al. (2012) shown in Figure 3. The equation has an upper-branch tipping point at a temperature of $2 \frac{1}{2}{ }^{\circ} \mathrm{C}$ and a volume of $70 \%$ of current volume. The lower branch has a tipping point at $1{ }^{\circ} \mathrm{C}$ and $25 \%$ of current volume. The equation has an equilibrium of zero volume at a temperature of 3.4 ${ }^{\circ} \mathrm{C}$. This cubic equation then replaced the linear equilibrium temperaturevolume relationship in the standard DICE-GIS model. The melt rate is reestimated to fit the Robinson data.

The major difference between the linear and hysteretic model is that the latter has a lower melt rate at the initial volume. This is easily seen in Figure 10 and results from the concavity of the function in the neighborhood of full volume. As a result, for the early years and a given temperature path, the GIS volume is higher with the hysteretic specification than with the linear specification. This result holds in all of the sixteen variants of discount rates and melt rates for the optimal and baseline runs. This finding is essentially inevitable if the two functions are tied down at the two ends $\left(0{ }^{\circ} \mathrm{C}\right.$ at $100 \%$ volume and 3.4 ${ }^{\circ} \mathrm{C}$ at $0 \%$ volume). 


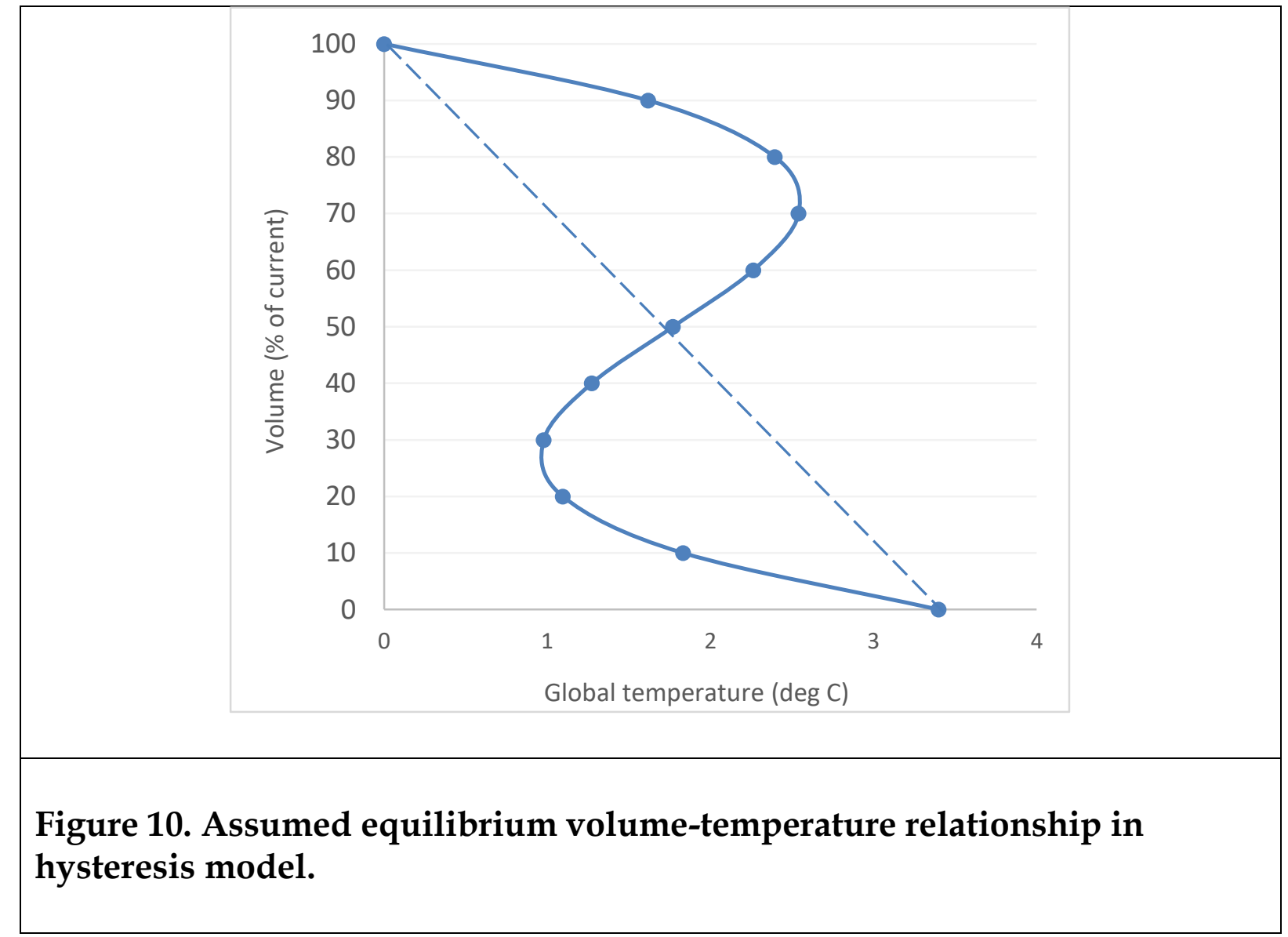

For the optimal policy, the results of the hysteretic model are very close to the linear model. The SCC for standard DICE parameters is $0.02 \%$ lower in the hysteretic case. The terminal volume (1500 years out) is higher in the hysteretic case: $85.4 \%$ v. $90.8 \%$ of volume for baseline parameters and $96.8 \%$ v. $97.8 \%$ for super-low discounting and the high melt rate.

For the baseline case, the results are more interesting. The SCC is lower in all cases for the hysteretic case (because of the lower initial melt rate). However, the ice sheet melts much faster once the threshold volume is passed, and this leads to much more rapid ice-sheet decline at that point. With no policy, therefore, complete disintegration occurs more rapidly with hysteresis.

So an interesting finding for the GIS is that the introduction of hysteresis makes little difference to the optimal policy. The reason is that the optimal policy stays away from the hysteretic threshold. However, for policies that pass the tipping point, hysteresis may make the outcome worse more quickly (although still very slowly).

\section{Uncertainty}

One of the paralytic features of analyzing climate change and particularly the role of the giant ice sheets is the presence of large uncertainties (see Figure 
4). An important question is how uncertainty would affect the outcomes and optimal policies.

To address this question, this study examined the very limited question of the effect of uncertainty about GIS variables. The experiment looked at the uncertainty of the melt rate and the damage coefficient. The distributions for each variable are assumed to be discrete with three equally likely values equal to $(0.5,1,1.5)$ times the deterministic value. This assumption produced nine equally likely states of the world. I then compared the expected value of the policies and outcomes for three discount rates: DICE discounting, 1\% per year, and $3 \%$ per year.

The impacts of uncertainty in the base and optimal cases were negligible. The SCC under uncertainty differed from the deterministic values by at most $1 / 2 \%$ for the six cases (optimal and base for three different discount rates). The GIS volumes differed by less than $1 \%$ at 500 years in the future.

The reason why uncertainty has so little effect is because the impact on the ice sheet is close to a linear function of the uncertain variables (see Nordhaus 2018 for a discussion of this point). Ice-sheet disintegration is a function of temperature-years, while temperature is a function of the stock of carbon concentrations, which in turn are a function of past emissions. Because of all the smoothing, shocks have a close-to-linear effect on all outcome and policy variables.ix

If the uncertainty involved quantitative constraints that triggered thresholds, uncertainty might be more important. For example, consider instead of a damage function that the optimization involves volumetric constraints with a mean value of $70 \%$, with the three values of $50 \%, 70 \%$, and $90 \%$. In the case of high discounting, the volume constraints would apply and raise the SCC by about $10 \%$. In the case of low discounting, the volume constraint would be met, and there would be no impact on the SCC. However, the impact of quantitative constraints depends critically on their levels as well as other parameters.

\section{Conclusion and Qualifications}

The present study incorporates a small model of the Greenland Ice Sheet (GIS) into the DICE integrated assessment model of the economics of climate change. The resulting model, DICE-GIS, allows an integrated study of the impact of economic activity and climate policy on emissions, concentrations, global and GIS temperature, GIS disintegration, sea-level rise, and damages. While all the different modules are simplified relative to high-resolution models, they have the advantage of integrating the different parts so that alternative policies can be assessed. 
The major results were provided in the introductory section. This section concludes with a discussion of some of the qualifications with the current analysis, focusing on the major issues that arise from adding the ice-sheet modeling. It leaves to the side standard issues of integrated assessment models such as DICE, which have been subject to vigorous attacks and defenses.

One major concern about including the GIS is that the equilibrium behavior is imperfectly understood. In particular, the question of whether there are single or multiple equilibria is not completely clear. The best evidence appears to be that there are multiple equilibria for global temperatures between $0{ }^{\circ} \mathrm{C}$ (pre-industrial) and $4{ }^{\circ} \mathrm{C}$. The evidence seems clear that virtually complete disintegration will eventually occur at global temperature increases above $6^{\circ} \mathrm{C}$, although "eventually" is many centuries.

A second issue is the transitory dynamics of disintegration. As the survey above indicates, current models provide highly divergent estimates of the melt rate at different temperatures. A multi-model survey gives a range of estimates of nearly a factor of four. The divergence arises because of the complexity of icesheet dynamics and the absence of a precise history of the transition in the paleoclimatic record.

A third uncertainty is the economic impact of sea-level rise. The most careful study to date (Diaz 2016) indicates that there is a range of a factor of ten for estimated impacts between a full-adaptation and a no-adaptation scenario. This uncertainty can be avoided by employing policies that constrain the disintegration of the GIS, but quantitative limits have the disadvantage of not having a strong economic basis.

Next, note that the present analysis is largely deterministic and provides only a cursory analysis of the impact of uncertainties on policies. As noted above, however, it seems unlikely that uncertainty will make a major difference for the social cost of carbon or ice-sheet disintegration.

Finally, it is necessary to emphasize the challenge of understanding the dynamics of geo-engineering strategies (or, more generally, strategies that return global temperatures back to pre-industrial or current levels). The present modeling, consistent with the sparse literature on the subject, finds there is a strong asymmetry between disintegration in a warm period and rebuilding the ice sheet in cooler periods. Determining whether this tentative finding is correct is an important issue for future research. 


\section{$\underline{\text { References }}$}

Alley, R.B., Andrews, J.T., Brigham-Grette, J., Clarke, G.K.C., Cuffey, K.M., Fitzpatrick, J.J., Funder, S., Marshall, S.J., Miller, G.H., Mitrovica, J.X., and Muhs, D.R. 2010. History of the Greenland Ice Sheet: paleoclimatic insights. Quaternary Science Reviews, 29 (1516), pp.1728-1756.

Applegate, P.J., Parizek, B.R., Nicholas, R.E., Alley, R.B., and Keller, K. 2014.

"Increasing temperature forcing reduces the Greenland Ice Sheet's response time scale" Climate Dynamics, 45 (7-8), pp.2001-2011.

Applegate, P.J. and Keller, K. 2015. “How effective is albedo modification (solar radiation management geo-engineering) in preventing sea-level rise from the Greenland Ice Sheet?" Environmental Research Letters, 10 (8), p.084018.

Bakker, A. M. R., Applegate, P. J., \& Keller, K. 2016. A simple, physically motivated model of sea-level contributions from the Greenland ice sheet in response to temperature changes. Environmental Modeling and Software, 83 (27-35).

Bakker, A. M. R., Wong, T. E., Ruckert, K. L., \& Keller, K. 2017. Sea-level projections representing the deeply uncertain contribution of the West Antarctic ice sheet. Scientific Reports, 7 (1), 3880.

Bindschadler, R.A., Nowicki, S., Abe-Ouchi, A., Aschwanden, A., Choi, H., Fastook, J., Granzow, G., Greve, R., Gutowski, G., Herzfeld, U., and Jackson, C. 2013. “Ice-sheet model sensitivities to environmental forcing and their use in projecting future sea level (the SeaRISE project)." Journal of Glaciology, 59 (214), pp.195-224.

Brock, W.A. and Starrett, D. 2003. “Managing Systems with Non-convex Positive Feedback," Environmental and Resource Economics, 26 (575-602).

Diaz, D. B. 2015. “Integrated Assessment of Climate Catastrophes with Endogenous Uncertainty: Does the Risk of Ice Sheet Collapse Justify Precautionary Mitigation?" FEEM discussion paper.

Diaz, D. B. 2016. “Estimating global damages from sea level rise with the Coastal Impact and Adaptation Model (CIAM)," Climatic Change, 137 (143-156).

Diaz, D. and Keller, K. 2016. "A potential disintegration of the West Antarctic Ice Sheet: Implications for economic analyses of climate policy," American Economic Review, 106 (5), pp.607-11.

Fürst, J.J., Goelzer, H., and Huybrechts, P. 2015. “Ice-dynamic projections of the Greenland ice sheet in response to atmospheric and oceanic warming," The Cryosphere, 9 (3), pp.1039-1062.

IPCC. 2013. Intergovernmental Panel on Climate Change, Climate Change 2013: The Physical Science Basis, Contribution of Working Group I to the Fifth Assessment Report 
of the IPCC, available online at http://www.ipcc.ch/report/ar5/wg1/\#.Ukn99hCBm71.

Keller, K., Bolker, B. M., \& Bradford, D. F. 2004. Uncertain climate thresholds and optimal economic growth, Journal of Environmental Economics and Management, 48 (1), pp.723-741.

Ridley, J., Gregory, J.M, Huybrechts, P., and Lowe, J. 2010. “Thresholds for irreversible decline of the Greenland ice sheet," Climate Dynamics, (10) 35, pp.1065-1073.

Nordhaus, W. 2014. Estimates of the social cost of carbon: concepts and results from the DICE-2013R model and alternative approaches, Journal of the Association of Environmental and Resource Economists, 1 (1/2), pp.273-312.

Nordhaus, W. 2018. "Projections and uncertainties about climate change in an era of minimal climate policies," American Economic Journal: Economic Policy, forthcoming.

Robinson, A., Calov, R., and Ganopolski, A. 2012. "Multistability and critical thresholds of the Greenland ice sheet," Nature Climate Change, 2 (6), p.429.

Somlyody, L. and Wets, R.J.-B. 1985. “Stochastic Optimization Models for Lake Eutrophication Management," IIASA Collaborative Paper, April.

Stern Review. 2007. The Economics of Climate Change: The Stern Review, Cambridge University Press: Cambridge, UK.

USWG. 2013. Interagency Working Group. 2013. Interagency Working Group on Social Cost of Carbon, United States Government, Technical Support Document: Technical Update of the Social Cost of Carbon for Regulatory Impact Analysis Under Executive Order 12866, May 2013, available at http://www.whitehouse.gov/sites/default/files/omb/ inforeg/social_cost_of_carbon_for_ria_2013_update.pdf.

Wong, T. E., Bakker, A. M. R., \& Keller, K. 2017. Impacts of Antarctic fast dynamics on sea-level projections and coastal flood defense, Climatic Change, 144 (2), pp.347-364. 


\section{Appendix A. Estimates of Melt Rates From Different Models}

This study examined different simulations of GIS models to determine the pattern of melt rates at different temperature profiles. Note that the term "melt rate" is used to denote the decrease in volume which is determined by the sum of runoff and glacial discharge minus precipitation.) There are multiple possible GIS approaches and results that can be used for developing the DICE-GIS model. The calibrations relied on the calculations of Robinson et al. 2012 (see Figure 4 of the main text) both because they show hysteresis in the simulations and because they have a complete trajectory for a wide range of temperature increases.

A comparison of the estimates from Robinson with other studies is shown in Figure 4 in the main text. Robinson et al. estimates are low for the lowest temperature increases $\left(2^{\circ} \mathrm{C}\right.$ global increase) but in the middle of the studies for the higher ones $\left(4\right.$ to $8^{\circ} \mathrm{C}$ ). There is considerable dispersion among studies, as is also shown by the SeaRise model comparison study (Bindschadler et al. 2013). Alternative studies differ by at least a factor of four in the studies shown in Figure 4, and by almost a factor of twenty in the high-temperature comparison (C3) in Bindschadler et al. The survey of models is shown in Table A-1. 


\begin{tabular}{|l|r|r|r|r|r|}
\hline \multicolumn{1}{|c|}{ Study } & $\begin{array}{c}\text { Temperature } \\
\text { change }\left({ }^{\circ} \mathrm{C},\right. \\
\text { GIS) }\end{array}$ & $\begin{array}{c}\text { Temperature } \\
\text { change }\left({ }^{\circ} \mathrm{C},\right. \\
\text { global) }\end{array}$ & $\begin{array}{c}\text { Sea-level rise } \\
(\mathrm{cm})\end{array}$ & $\begin{array}{c}\text { Sea-level } \\
\text { rise }\left[\mathrm{cm} /{ }^{\circ} \mathrm{C}\right. \\
\text { GIS-century] }\end{array}$ & $\begin{array}{c}\text { Sea-level rise } \\
\text { [cm/ }{ }^{\circ} \mathrm{C} \text { global- } \\
\text { century] }\end{array}$ \\
\hline Bindschadler & 3.10 & 2.07 & 19.0 & 1.23 & 1.84 \\
Bindschadler & 4.70 & 3.13 & 39.0 & 1.66 & 2.49 \\
Bindschadler & 6.20 & 4.13 & 73.0 & 2.35 & 3.53 \\
Furst & 1.05 & 0.70 & 4.2 & 4.03 & 6.04 \\
Furst & 1.80 & 1.20 & 5.5 & 3.06 & 4.58 \\
Furst & 2.00 & 1.33 & 5.4 & 2.70 & 4.05 \\
Furst & 3.58 & 2.38 & 10.2 & 2.84 & 4.26 \\
Furst & 2.60 & 1.73 & 8.8 & 1.13 & 1.69 \\
Furst & 5.30 & 3.53 & 20.1 & 1.26 & 1.90 \\
Applegate & 3.00 & 2.00 & 17.5 & 1.75 & 2.63 \\
Applegate & 4.50 & 3.00 & 42.3 & 2.82 & 4.23 \\
Applegate & 6.00 & 4.00 & 94.4 & 4.72 & 7.08 \\
Applegate & 12.00 & 8.00 & 490.7 & 12.27 & 18.40 \\
Ridley & 4.50 & 3.00 & 26.1 & 1.16 & 1.74 \\
Ridley & 6.00 & 4.00 & 40.9 & 1.36 & 2.04 \\
Ridley & 7.50 & 5.00 & 61.3 & 1.64 & 2.45 \\
Ridley & 9.00 & 6.00 & 85.6 & 1.90 & 2.85 \\
Robinson & 2.00 & 2.22 & 7.4 & 0.74 & 0.67 \\
Robinson & 4.00 & 4.44 & 57.2 & 2.83 & 2.57 \\
Robinson & 6.00 & 6.67 & 116.2 & 3.83 & 3.48 \\
Robinson & 8.00 & 8.89 & 232.3 & 5.75 & 5.23 \\
DICE-GIS & & 2.00 & 14.4 & 1.44 & 1.44 \\
DICE-GIS & & 6.00 & 119.6 & 3.99 & 3.13 \\
DICE-GIS & 6.00 & 203.9 & 5.10 & 5.10 \\
DICE-GIS & 8.00 & & & \\
\hline
\end{tabular}

Table A-1. Selection of melt rates, alternative studies.

These estimates are the melt rate for the first 100 - 500 years in the different studies. Note that the melt rates are close to linear in the SLRe per year per ${ }^{\circ} \mathrm{C}$ warming. This finding is confirmed for the detailed estimates in the Robinson simulations discussed in Appendix B. ${ }^{x}$ 


\section{Appendix B. Estimates of Melt-Rate Function for DICE-GIS}

The DICE-GIS model used the simulations from Robinson et al. (2012). These data were provided by Prof. Robinson. The data come in steps of 10 years for model runs of 5000 years. The temperature trajectory was a linear ramp from $0{ }^{\circ} \mathrm{C}$ to the target, over a period of 100 years. The regressions used only four target trajectories $\left(2,4,6\right.$, and $\left.8^{\circ} \mathrm{C}\right)$ for the estimates. The authors state that the global mean temperature is $90 \%$ of the summer temperature used for the runs, so the ice-sheet temperature was converted to global mean temperature by multiplying each of the targets by 1.111 .

There were several estimates of the melt-rate function. The central equation was the following:

$$
\Delta V(t) / \Delta t=\alpha\left[T(t)-T^{*}(t)\right]^{\beta}[V(t) / 100]^{\gamma}
$$

In unconstrained form, this yielded:

\begin{tabular}{|c|c|c|c|c|}
\hline \multicolumn{5}{|c|}{$\begin{array}{l}\text { Dependent Variable: DVOL } \\
\text { Method: Least Squares (Gauss-Newton / Marquardt steps) } \\
\text { Sample: } 14004 \text { IF TIME }>200 \text { AND TIME }<3000 \\
\text { Included observations: } 2236 \\
\text { Convergence achieved after } 25 \text { iterations } \\
\text { Coefficient covariance computed using outer product of gradients } \\
\text { DVOL }=C(1)^{\star}(\text { TEMP-TEMPSTAR })^{\wedge} \mathrm{C}(2)^{\star}(\mathrm{VOL}(-1) / 100)^{\wedge} \mathrm{C}(3)\end{array}$} \\
\hline & Coefficient & Std. Error & t-Statistic & Prob. \\
\hline$C(1)$ & -0.006195 & 0.000206 & -30.10993 & 0.0000 \\
\hline$C(2)$ & 1.905958 & 0.017477 & 109.0539 & 0.0000 \\
\hline$C(3)$ & 0.166714 & 0.005545 & 30.06532 & 0.0000 \\
\hline R-squared & 0.895398 & \multirow{6}{*}{\multicolumn{2}{|c|}{$\begin{array}{l}\text { Mean dependent var } \\
\text { S.D. dependent var } \\
\text { Akaike info criterion } \\
\text { Schwarz criterion } \\
\text { Hannan-Quinn criter. }\end{array}$}} & -0.098951 \\
\hline Adjusted R-squared & 0.895305 & & & 0.083842 \\
\hline S.E. of regression & 0.027128 & & & -4.375132 \\
\hline Sum squared resid & 1.643374 & & & -4.367468 \\
\hline Log likelihood & 4894.398 & & & -4.372334 \\
\hline Durbin-Watson stat & 0.004368 & & & \\
\hline
\end{tabular}

\section{Table B-1. Unconstrained melt-rate equation.}

For numerical optimization in the GAMS algorithm, $\beta$ is set equal to 2 and $\gamma$ is rounded to 0.2 . This yields the following equation which has a virtually identical fit for the period. Note that the calibration starts at 200 years because the spin-up has erratic behavior. 


\begin{tabular}{|c|c|c|c|c|}
\hline \multicolumn{5}{|c|}{$\begin{array}{l}\text { Dependent Variable: DVOL } \\
\text { Method: Least Squares (Gauss-Newton / Marquardt steps) } \\
\text { Sample: } 14004 \text { IF TIME>200 AND TIME<3000 } \\
\text { Included observations: } 2236 \\
\text { DVOL }=C(1)^{*}(\text { TEMP-TEMPSTAR })^{\wedge} 2^{*}(\mathrm{VOL}(-1) / 100)^{\wedge} 0.2\end{array}$} \\
\hline & Coefficient & Std. Error & t-Statistic & Prob. \\
\hline$C(1)$ & -0.005303 & 2.44E-05 & -216.8998 & 0.0000 \\
\hline R-squared & 0.891448 & \multirow{6}{*}{\multicolumn{2}{|c|}{$\begin{array}{l}\text { Mean dependent var } \\
\text { S.D. dependent var } \\
\text { Akaike info criterion } \\
\text { Schwarz criterion } \\
\text { Hannan-Quinn criter. }\end{array}$}} & -0.098951 \\
\hline Adjusted R-squared & 0.891448 & & & 0.083842 \\
\hline S.E. of regression & 0.027624 & & & -4.339847 \\
\hline Sum squared resid & 1.705444 & & & -4.337292 \\
\hline Log likelihood & 4852.949 & & & -4.338914 \\
\hline Durbin-Watson stat & 0.004227 & & & \\
\hline
\end{tabular}

\section{Table B-2. Preferred melt-rate equation.}

The model outputs (Robinson) and DICE-GIS equation fit from Table B-2 are shown in Figure B-1. The fit is reasonably close for the present purposes. The model overpredicts the melt at the lowest temperature and has the wrong tilt in the middle-temperature ranges, but the overall fit is very strong.

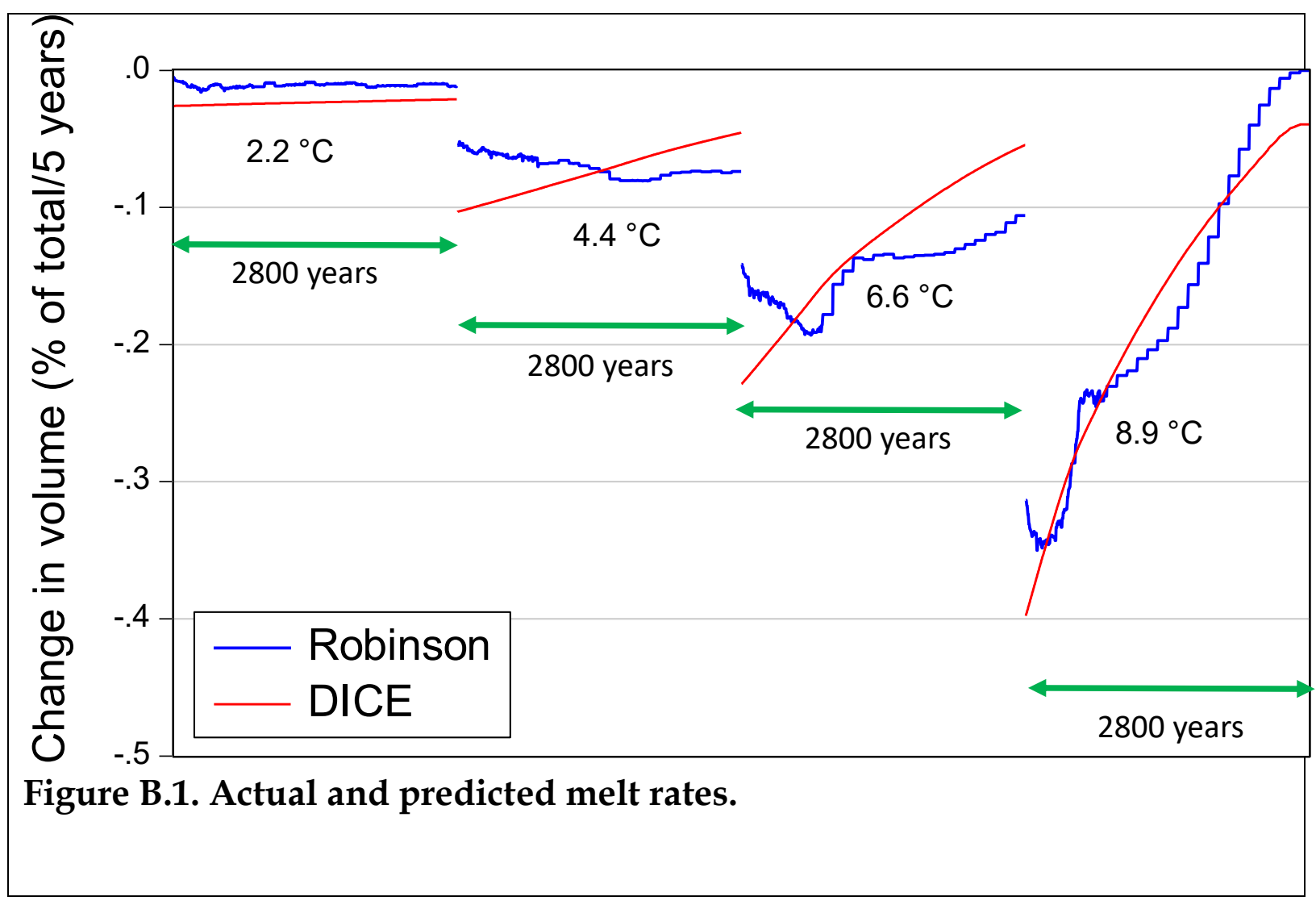


As a final model output, Figure B-2 shows the trajectory for GIS volume with the $8.9^{\circ} \mathrm{C}$ global warming. The static DICE uses actual lagged volume in the simulation, while dynamic DICE uses projected volumes. Both are very close to the Robinson trajectory. The summary is that the DICE-GIS can simulate the Robinson et al. calculations reasonably closely. The major issue is the difference across different GIS models (as shown in Appendix A), not the difference between the DICE-GIS and the Robinson simulations.

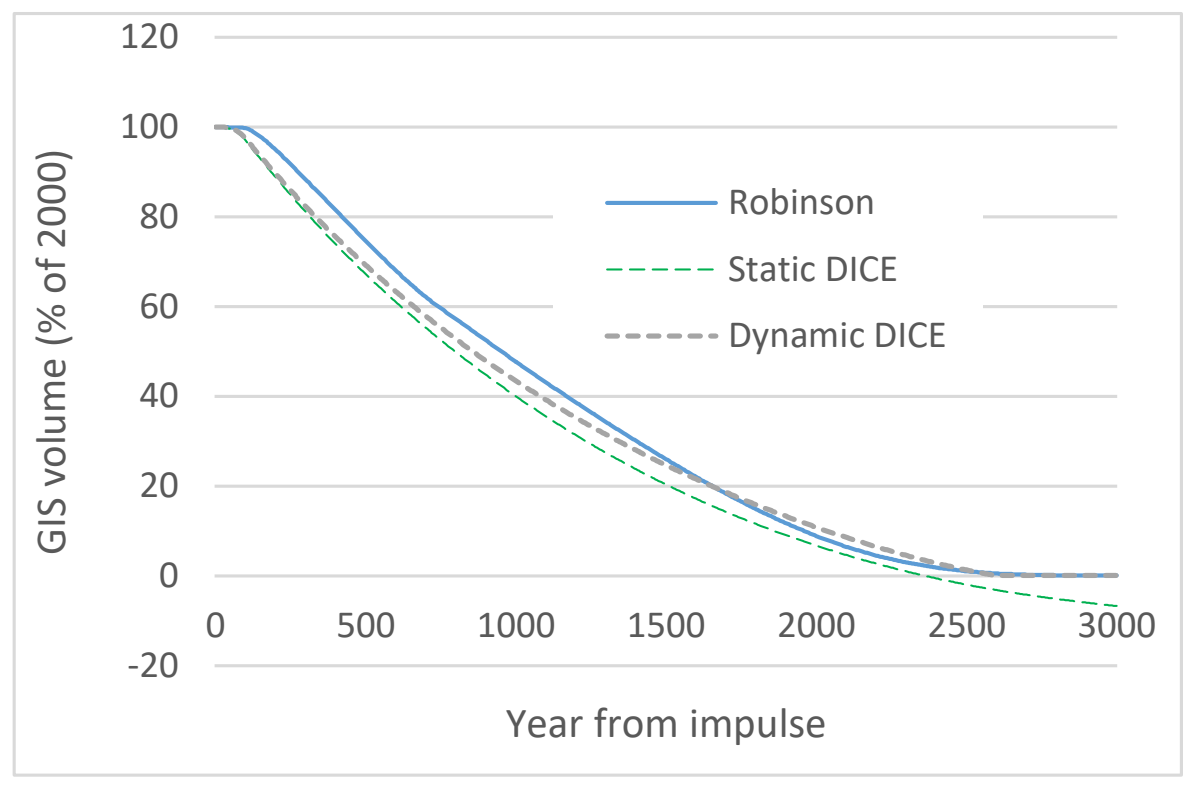

Figure B-2. Trajectories on GIS volume with Robinson and two alternative calculations for global warming of $8.9^{\circ} \mathrm{C}$ global. ${ }^{\mathrm{i}}$ 


\section{Appendix C. Estimates of melt rates from different models ${ }^{x i i}$}

This appendix explains the derivation of the melt rates in the different models.

1. Furst et al. (2015)

This paper uses temperature over the ice sheet, apparently annual. It calculates using four temperature paths to 2100 and two to 2300 . The following shows the basic results. The results are not intuitive as 2300 is not much higher than 2100 .

Table 4. Ice-sheet-wide mean atmospheric warming, basin-mean oceanic warming, and ensemble-average contribution of the Greenland ice sheet to global sea-level change by 2100 and 2300. Sea-level changes are calculated with respect to the year 2000. Ensemble averages for each scenario use equal weights for individual AOGCMs. The root mean square deviation from the mean ensemble realisation is added to estimate the variability.

\begin{tabular}{|c|c|c|c|c|c|c|}
\hline \multicolumn{4}{|c|}{2100} & \multicolumn{3}{|c|}{2300} \\
\hline $\begin{array}{l}\text { Climate } \\
\text { scenario }\end{array}$ & $\begin{array}{r}\text { Atmospheric } \\
\text { warming } \\
\left({ }^{\circ} \mathrm{C}\right)\end{array}$ & $\begin{array}{r}\text { Oceanic } \\
\text { warming } \\
\left({ }^{\circ} \mathrm{C}\right)\end{array}$ & $\begin{array}{r}\text { Sea-level } \\
\text { contribution } \\
(\mathrm{cm} s .1 . e .)\end{array}$ & $\begin{array}{r}\text { Atmospheric } \\
\text { warming } \\
\left({ }^{\circ} \mathrm{C}\right)\end{array}$ & $\begin{array}{r}\text { Oceanic } \\
\text { warming } \\
\left({ }^{\circ} \mathrm{C}\right)\end{array}$ & $\begin{array}{r}\text { Sea-level } \\
\text { contribution } \\
(\mathrm{cm} \text { s.l.e. })\end{array}$ \\
\hline $\mathrm{RCP} 2.6$ & $2.10 \pm 1.53$ & $1.12 \pm 0.57$ & $4.23 \pm 1.80$ & $2.59 \pm 1.62$ & $1.32 \pm 0.73$ & $8.82 \pm 4.48$ \\
\hline $\mathrm{RCP} 4.5$ & $3.56 \pm 1.86$ & $1.62 \pm 0.67$ & $5.50 \pm 1.86$ & $5.27 \pm 1.62$ & $2.77 \pm 1.18$ & $20.11 \pm 8.03$ \\
\hline $\mathrm{RCP} 6.0$ & $4.00 \pm 1.59$ & $1.43 \pm 0.22$ & $5.40 \pm 1.49$ & - & - & - \\
\hline $\mathrm{RCP} 8.5$ & $7.15 \pm 1.98$ & $2.68 \pm 0.94$ & $10.15 \pm 3.24$ & - & - & - \\
\hline
\end{tabular}

2. Bindschadler et al. (2103)

This study is a model comparison. However, the results are sometimes difficult to decipher. The major problem is understanding the temperature trajectories associated with the different scenarios. We have chosen only C1 - C3 as these seem clearest. Additionally, concentrate on the 500 -year results. $\mathrm{C} 1$ is the A1B scenario from the IPCC, while $\mathrm{C} 2$ is 1.5 times $\mathrm{C} 1$ and $\mathrm{C} 3$ is two times $\mathrm{C} 1$. The following shows the basic results.

Table 3. Global sea-level increase $(\mathrm{cm})$ projected by SeaRISE models for each experiment at 100, 200 and 500 years since model initial time of 1 January 2004

\begin{tabular}{|c|c|c|c|c|c|c|c|c|c|}
\hline & \multicolumn{3}{|c|}{100} & \multicolumn{3}{|c|}{200} & \multicolumn{3}{|c|}{500} \\
\hline & Min & Mean & $\operatorname{Max}$ & Min & Mean & $\operatorname{Max}$ & Min & Mean & $\operatorname{Max}$ \\
\hline \multicolumn{10}{|c|}{ Greenland } \\
\hline C1 & 0.9 & 3.3 & 6.6 & 1.2 & 7.4 & 15.5 & 5.4 & 19.2 & 38.7 \\
\hline $\mathrm{C} 2$ & 1.3 & 6.1 & 12.4 & 1.8 & 14.5 & 32.0 & 7.2 & 39.2 & 79.8 \\
\hline C3 & 1.8 & 10.2 & 21.4 & 2.3 & 25.3 & 56.2 & 8.5 & 72.6 & 142.6 \\
\hline M1 & 0.0 & 2.7 & 12.5 & 0.0 & 3.1 & 16.6 & -0.1 & 4.5 & 22.0 \\
\hline M2 & 1.0 & 13.5 & 58.2 & 0.0 & 13.7 & 66.2 & -0.1 & 18.5 & 78.1 \\
\hline M3 & 1.6 & 24.9 & 83.3 & -0.1 & 24.1 & 87.5 & -0.2 & 30.1 & 97.5 \\
\hline S1 & 1.6 & 6.9 & 13.0 & 2.8 & 11.5 & 22.4 & 5.0 & 17.0 & 29.1 \\
\hline S2 & 2.2 & 10.5 & 22.9 & 3.9 & 17.0 & 38.0 & 7.2 & 24.3 & 42.2 \\
\hline S3 & 2.9 & 14.6 & 35.0 & 5.0 & 23.4 & 55.2 & 9.0 & 30.9 & 54.3 \\
\hline C1S1 & 6.6 & 10.2 & 15.2 & 13.6 & 18.8 & 27.4 & 26.9 & 36.8 & 47.4 \\
\hline
\end{tabular}

The following shows the results for individual models. Note that the units are $40 \times 10^{14} \mathrm{~m}^{3}=1 \mathrm{~m}$ SLRe. 

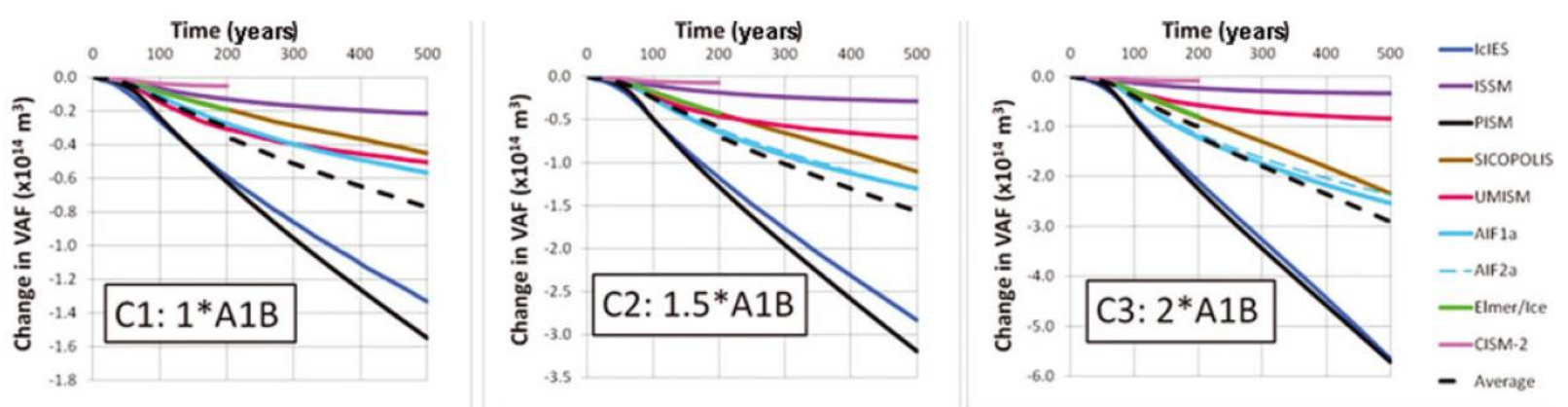

3. Patrick J. Applegate, Byron R. Parizek, Robert E. Nicholas, Richard B. Alley and Klaus Keller (2014)

Applegate et al. (2014) do simulations of the SCIOPOLIS model and use it to calibrate a small model for use in experiments. I was unable to get numerical values of their simulations, and the estimates here may be unreliable. Estimates in the text were derived from Figure 3, reproduced below.

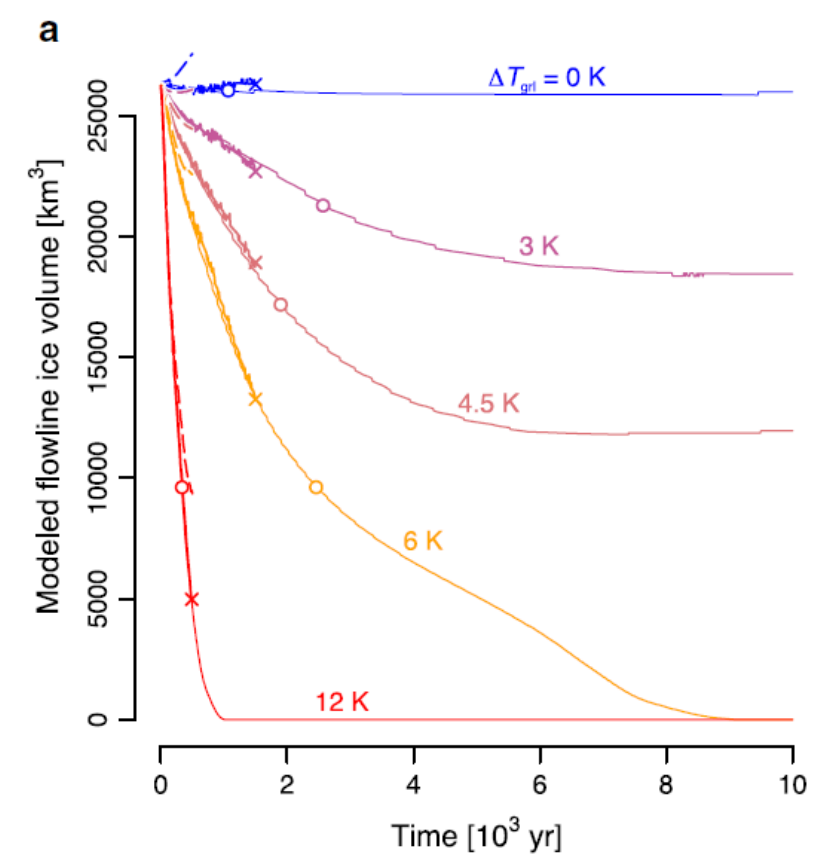

4. Jeff Ridley, Jonathan M. Gregory, Philippe Huybrechts, and Jason Lowe (2010)

This study was explained in the text. The major results are from the following table. 
Table 1 Time required in years, to the nearest decade, to reduce the volume of the Greenland ice sheet by $10 \%$, for various steady-state global warmings with respect to pre-industrial climate

\begin{tabular}{ll}
\hline $\begin{array}{l}\text { Global temperature } \\
\text { rise }\left({ }^{\circ} \mathrm{C}\right)\end{array}$ & $\begin{array}{l}\text { Median time to melt } \\
10 \% \text { of ice volume (years) }\end{array}$ \\
\hline 3 & 1,410 \\
4 & 900 \\
5 & 600 \\
6 & 430 \\
\hline
\end{tabular}

Relative to the average climate of 1980-1999, the warmings would be about $0.5^{\circ} \mathrm{C}$ less. For each warming, the rate of mass loss is calculated using the range of model sensitivities evaluated by Gregory and Huybrechts (2006), and we show the median of the model range

Note also the dynamics of geo-engineering, which show near irreversibility, from Ridley et al. (2010).

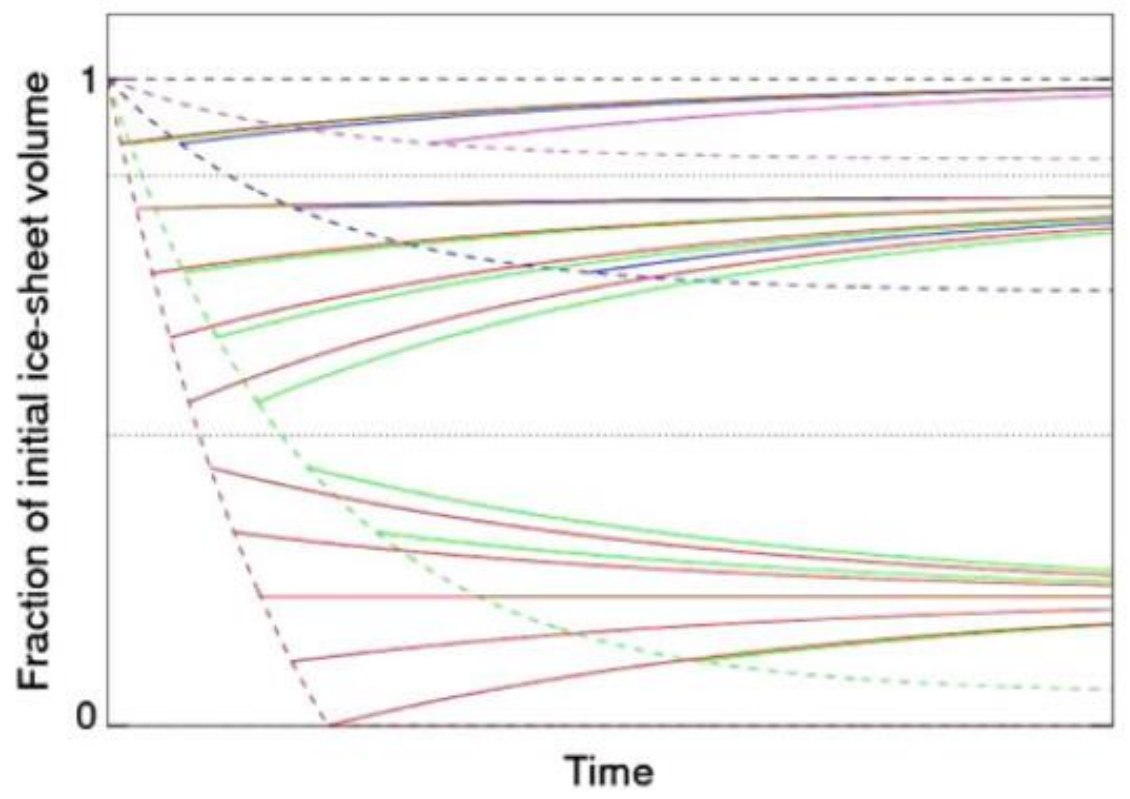

Fig. 7 Schematic diagram showing the future evolution of the Greenland ice sheet for four different levels of climatic warming, each maintained for a range of times, after which the climate reverts to pre-industrial. The colours indicate the climatic warming, purple for least and red for most; the ice sheet contracts faster in warmer climates. The dashed lines are the phase during which the warming is applied, and the solid lines the subsequent recovery phase towards three different steady states. The dotted horizontal lines are thresholds of irreversibility (points of no return). Thresholds of sustainability (tipping points) cannot easily be shown on this diagram; they are temperature thresholds, and correspond roughly to different initial rates of contraction. The diagram is not intended to be quantitative 


\section{IPCC (2013), Chapter 13}

The IPCC repeats the studies reviewed above. It concludes that there is a threshold, but they cannot determine where it is. The conclusion of the IPCC report is as follows:

With currently available information, we do not have sufficient confidence to assign a likely range for the threshold. If the threshold is exceeded temporarily, an irreversible loss of part or most of the Greenland ice sheet could result, depending on the duration and amount that the threshold is exceeded. ( $p$ 1169)

The available evidence indicates that sustained global warming greater than a certain threshold above pre-industrial would lead to the near-complete loss of the Greenland ice sheet over a millennium or more, causing a global mean sea level rise of about $7 \mathrm{~m}$. Studies with fixed ice-sheet topography indicate the threshold is greater than $2^{\circ} \mathrm{C}$ but less than $4^{\circ} \mathrm{C}$ (medium confidence) of global mean surface temperature rise concerning pre-industrial. The one study with a dynamical ice sheet suggests the threshold is greater than about $1^{\circ} \mathrm{C}$ (low confidence) global mean warming concerning pre-industrial. We are unable to quantify a likely range. Whether or not a decrease in the Greenland ice sheet mass loss is irreversible depends on the duration and degree of exceedance of the threshold. Abrupt and irreversible ice loss from a potential instability of marine-based sectors of the Antarctic ice sheet in response to climate forcing is possible, but current evidence and understanding are insufficient to make a quantitative assessment. $\{5.8,13.3,13.4\}$ (p. 1140) 


\section{Appendix D. Equations of the GAMS Model to Include Greenland Ice Sheet}

The following are the equations for the module of the Greenland Ice Sheet. The listing omits boundary conditions and some small details that are used to ensure numerical stability.

Variables in GriSh Model for GAMS code

$$
\begin{array}{ll}
V(t) & =\text { volume GIS (fraction of current volume) } \\
T^{*}(t) & =\text { equilibrium temperature-volume relationship } \\
V \operatorname{dot}(t) & =\text { change in } \mathrm{V}(\mathrm{t}) \text { per } 5 \text { years } \\
T D(t) & =\mathrm{T}(\mathrm{t}) \text { minus } \mathrm{T} *(\mathrm{t}) \\
\operatorname{SLR}(t) & =\text { Sea level rise from } 2000 \\
\operatorname{sgn}(T D(t)) & =\text { Sign of TD }(1 \text { if positive, }-1 \text { if negative) }
\end{array}
$$

\section{GriSh equations}

$$
\begin{aligned}
& V(t)=V(t-1)+V \operatorname{dot}(t) \\
& T^{*}(t)=3.4(1-V(t)) \\
& S L R(t)=7.0 *(1-V(t)) \\
& T D(t)=T(t)-T^{*}(t) \\
& V \operatorname{dot}(t)=-.0053 \operatorname{sgn}[T D(t)] T D(t)^{2} V(t)^{0.2}
\end{aligned}
$$




\section{Appendix E. GAMS Code for GIS Equations}

The following are the key equations added to the standard DICE-2016R2 model. The full model will be available anon.

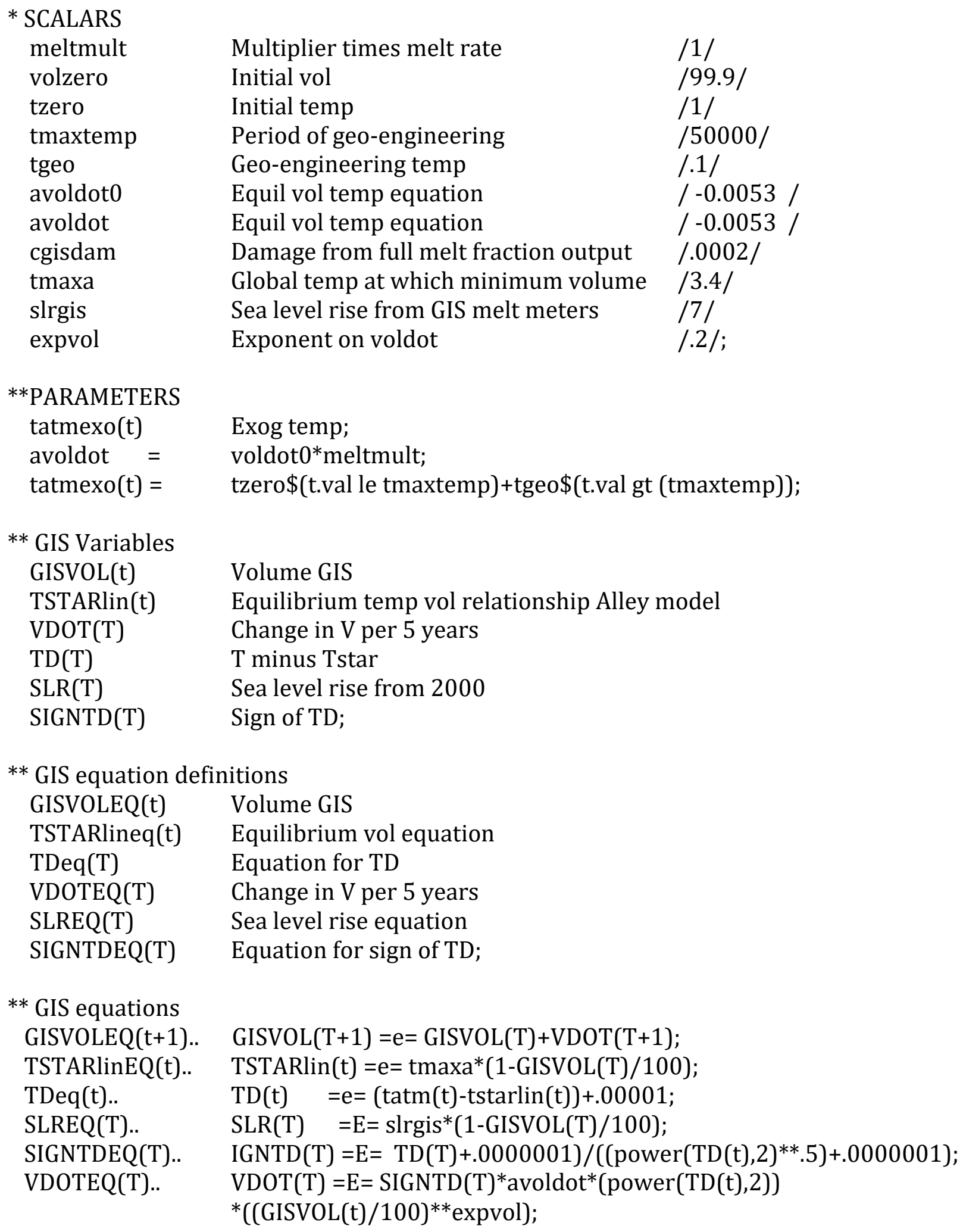

